\title{
El dominio inca en la localidad de Caspana: Un acercamiento al pensamiento político andino (río Loa, norte de Chile) ${ }^{1}$
}

\author{
Leonor Adán A. ${ }^{2}$ y Mauricio Uribe R. ${ }^{3}$
}

\begin{abstract}
RESUMEN
Se presenta el registro arqueológico de cinco sitios tardios de la localidad de Caspana con el objeto de problematizar la naturaleza de la expansión incaica en las tierras altas del río Loa, Desierto de Atacama. Una primera sistematización de estos yacimientos permite distinguir: a) asentamientos de la población local con una débil incorporación de elementos incaicos, como es el caso de los sitios Aldea Talikuna y Estancia Mulorojte; b) instalaciones mineras, agrícolas y/o ganaderas incas como los sitios Cerro Verde, Incahuasi Inca y Vega Salada, y c) lugares compartidos donde se despliegan ambas identidades dentro de un contexto fuertemente simbólico, correspondiente al Cementerio de Los Abuelos. El análisis de la cultura material de estos sitios sugiere diferencias y similitudes significativas que resultarían de una estrategia de dominio directo y planificado sobre estos territorios por parte del Tawantinsuyu, así como simbólicamente complejo y elaborado.
\end{abstract}

Palabras claves: dominio inca - Caspana - arqueología del poder.

\section{ABSTRACT}

This paper presents the archaeological record for five late pre-Hispanic sites located in Caspana, in order to discuss Inca expansion in the upper river Loa basin (Atacama Desert). A first categorization of these sites enables to establish a distinction between: a) locals settlements with low presence of inca features -the case of Aldea Talikuna and Estancia Mulorojte; b) pure inca settlements, which include Cerro Verde, Incahuasi Inca and Vega Salada -mineral, agricultural and/or cattle sites, and c) shared settlements where both identities are displayed in a symbolically laden context-like Los Abuelos cemetery. Our analysis of the material culture associated to these sites suggests a set of significant differences and similarities that would be the result of a direct and planned ruling strategy deployed by the Inca State through elaborately complex symbolical means.

Key words: Inca rule - Caspana - archaeology of power.

Recibido: enero 2004. Manuscrito revisado aceptado: agosto 2004.

1 Proyecto FONDECYT 1970528.

2 Dirección Museológica, Universidad Austral de Chile, Valdivia. Museo Histórico de Valdivia Mauricio Van de Maele, Los Laureles s/nº Isla Teja, Valdivia, CHILE. Email: ladan@uach.cl

\section{Introducción}

La abundancia de restos incaicos $-\mathrm{O}$ asociados a su expansión- a lo largo de gran parte del territorio chileno ha convertido la problemática incaica en uno de los temas más atractivos para los estudios arqueológicos del país. Pese a lo anterior, tal temática ha recibido una atención indirecta u ocasional, notándose una falta de continuidad en su tratamiento, lo cual ha contribuido a un escaso aprovechamiento de las potencialidades que podrían entregar esos restos materiales, así como la abundante historia documental y oral existente respecto al problema en el mundo andino. Esta ausencia de una línea temática de investigación se traduce en una mínima comprensión del impacto del Tawantinsuyu en el país tal como observan algunos colegas:

"Las noticias que hemos entregado en este recuento, nos permiten evaluar cuán poco sabemos aún de la ocupación incaica en la región y cuánto trabajo básico es necesario desarrollar para contar con los datos que permitan comprender esta fase de la prehistoria regional y las distintas modalidades de las estrategias de ocupación del espacio por parte de los incas. Probablemente un programa de largo alcance, en el que participen varios grupos de trabajo, con estrategias y técnicas de investigación que integren criterios metodológicos comunes, logren avances significativos en relación a este problema" (Castro 1992: 152).

De tal modo, esta carencia plantea la necesidad de efectuar reflexiones sistemáticas en torno a la dinámica del encuentro entre grupos diferentes, dentro del proceso expansivo de un Estado como el Tawantinsuyu y con un referente espacial concreto como en nuestro caso son las quebradas altas del Loa Superior. Esto permitiría acceder a

\footnotetext{
3 Departamento de Antropología, Facultad de Ciencias Sociales, Universidad de Chile. Ignacio Carrera Pinto 1045, Ñuñoa. Santiago, CHILE. Email: mur@uchile.cl
} 
planos distintos de interpretación, desde los históricos culturales (etapas de la expansión) hasta otros más sustantivos (políticos y simbólicos). Nuestra opinión es que esta tarea es factible de ser desarrollada arqueológicamente con el apoyo y la complementariedad de los datos surgidos de una gran cantidad y variedad de documentos coloniales, y también por la valiosa historia oral existente en la región sobre el "Rey Inka".

El trabajo que se presenta a continuación se enmarca en este contexto y da cuenta de la formulación del problema y los avances en la investigación interdisciplinaria que hemos desarrollado. ${ }^{4}$

\section{Arqueología y prehistoria de la localidad de Caspana}

La localidad de Caspana está ubicada a $85 \mathrm{~km}$ al noreste de la ciudad de Calama, en la Provincia de El Loa, II Región (22 20' Lat. Sur y 68 14' Long. Oeste), emplazada a una altura de 3200 m.snm (Figura 1). La comunidad indígena de Caspana reconoce como límites territoriales los cerros de Tatio por el este, el río Salado por el norte (límite con la localidad de Toconce), la confluencia de los ríos Salado con el Caspana por el oeste (límite con la de Aiquina) y la localidad de Río Grande por el sur.

Como resultado de investigaciones arqueológicas realizadas en la localidad desde el año 1994, se definió una secuencia cronológica cultural con especial énfasis en los períodos agroalfareros (Adán y Uribe 1995; Adán et al. 1995). Los resultados de esta secuencia nos permiten enfrentar la problemática incaica con un conocimiento global de la historia cultural de Caspana.

En este cuadro se distingue un primer período que hemos llamado de las Tradiciones Tempranas, caracterizado por una débil ocupación de la localidad, comparada con lo que ocurre contemporáneamente en el Loa Medio y en la cuenca del Salar

4 El equipo de investigación estuvo conformado por los arqueólogos Victoria Castro, Varinia Varela, Patricia Ayala, Carlos Carrasco y Flora Vilches, y por la etnohistoriadora Viviana Manríquez. Además, se consultó la opinión de especialistas, como Joyce Strange, en antropología física; del geólogo Alejandro Díaz, sobre minería y geología, y del agrónomo Marcelo Gamboa, para los sistemas agronómicos y recursos hídricos. de Atacama (Pollard 1982 [1970]; Bittman et al. 1978), y en períodos posteriores de Caspana mismo. Para la época en cuestión, en las mesetas altas se identificaron sitios habitacionales de planta circular y semihundidos o depresionados, cercanos a cursos de agua permanente. Dos de ellos de magnitudes considerables son Turicuna e Incahuasi Temprano. El patrón constructivo de estos sitios los emparenta con sitios tempranos del Salar de Atacama como aquellos de la quebrada de Tulan (Núñez 1981).

Otro tipo de sitios con ocupaciones asignables a las Tradiciones Tempranas son los aleros asociados a manifestaciones de arte rupestre en las quebradas (p.e., Las Oquedades, Doña Marta y El Pescador).

Ambos tipos de sitios comparten materiales líticos y alfareros, cuyas distribuciones particulares sugieren una utilización diferencial del espacio en directa relación con las actividades desarrolladas por grupos cazadores recolectores, integrados a un circuito de transhumancia y con cierto grado de sedentarismo inicial o semisedentarismo (Carrasco 1996). Por su parte, la escasa cerámica recuperada en estos sitios, si bien es asignable a la tradición negra pulida, los vincula más a épocas formativas que al clásico Período Medio de San Pedro de Atacama (Sinclaire et al. 2000).

En suma, la ocupación alfarera temprana de la localidad de Caspana indica la presencia de grupos humanos de tradición cazadora recolectora, correspondientes al Período Arcaico Tardío y/o Formativo Temprano, los cuales poseen una manera organizada de procurarse refugio y mantienen amplios circuitos de movilidad que los vincula al Complejo Chiu Chiu y a los desarrollos del Salar de Atacama, zonas a las que no sólo están accediendo por el material artefactual, sino también por la ubicación de los yacimientos (Carrasco 1996). Por otra parte, algunas de las dataciones obtenidas para estas ocupaciones, por ejemplo, $565 \pm 150 \mathrm{DC}$ en el sitio Incahuasi Temprano (UCTL 727), señalan una persistencia de estas tradiciones en las tierras altas del Loa, mientras en su curso medio y en San Pedro de Atacama se desarrollan complejas formaciones sociales agroalfareras en lo que se conoce como Período Medio atacameño. La permanencia de estas tradiciones se debe, seguramente, a las condiciones ecológicas de la localidad de Caspana, donde se requiere de especializados conocimientos 


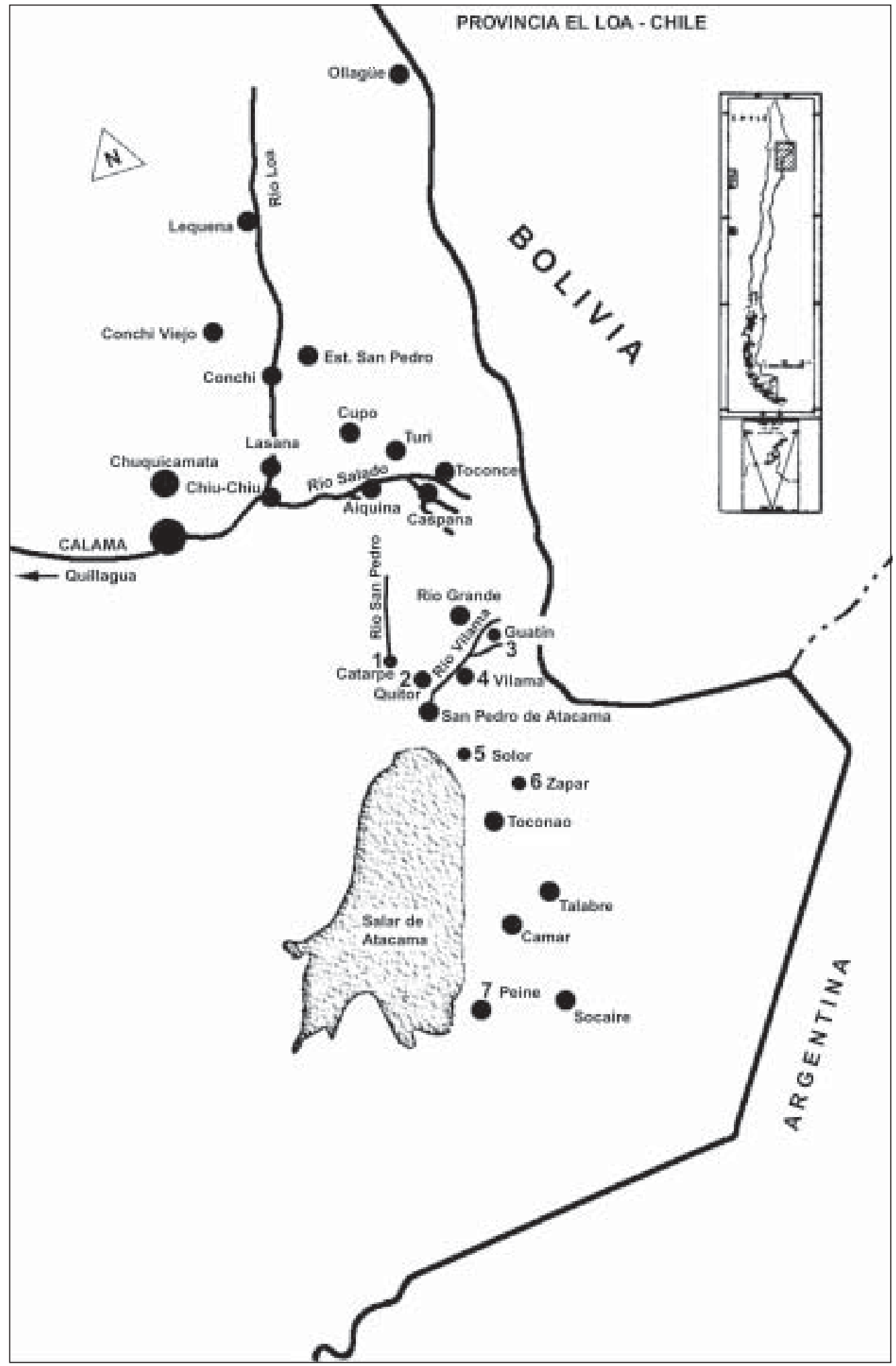

Figura 1. Mapa de la región atacameña y principales localidades mencionadas en el texto. 
para el desarrollo de la agricultura, actividad productiva fundamental de las sociedades del Período Medio.

Durante el Período Intermedio Tardío parece revertirse la situación anterior, intensificándose la dinámica de las tierras altas del territorio en cuestión. Paralelo a una mayor intensidad de la ocupación, en Caspana se observa una diversificación de los espacios utilizados y de los tipos de asentamientos. Se registra una importante concentración poblacional en la Aldea Talikuna de la quebrada homónima con fechas absolutas que van desde el 1100 DC hasta el 1450 DC, un uso estanciero de diferentes sectores asociados a extensos campos de cultivo y/o pastoreo como es el caso de la Estancia Mulorojte y cementerios aglutinados así como dispersos. El Cementerio de Los Abuelos constituye una importante expresión de la ocupación de la quebrada de Caspana que, con probabilidad, se relacionó a un asentamiento previo donde actualmente se levanta el Pueblo Viejo de la comunidad, de origen colonial. En definitiva, se ocupan las quebradas y todos los cursos de agua dulce permanente, el área de Cablor y las mesetas altas en general, puesto que se desarrolla una intensa actividad agrícola, complementada con el tradicional pastoreo.

Esta vez, la alfarería presente en los asentamientos indica la existencia de una fuerte esfera de interacción Loa-San Pedro que se mantiene en estrecho vínculo con los desarrollos vecinos en el Altiplano Meridional y el Noroeste Argentino.

Como ya lo hemos propuesto (Adán y Uribe 1995; Uribe y Adán 1995), estamos ante la presencia de sociedades complejas que conocen en profundidad el medio que ocupan y poseen las tecnologías apropiadas para su aprovechamiento. El registro material indica sociedades que comparten un sustrato común territorialmente muy extendido, con mayor o menor cercanía a algunos centros que han sido considerados focos de gravitación cultural. Caspana, en este sentido, participa de una tradición de tierras altas donde se funde lo altiplánico y lo propiamente "atacameño", permitiéndole a su desarrollo alcanzar en este período el mayor éxito, lo que resulta del todo evidente en el vecino y monumental Pucara de Turi.

Estos territorios que, como hemos dicho, están siendo intensamente ocupados por sociedades con organizaciones bastante complejas, sin duda, constituyeron un polo de atracción para el Tawantinsuyu, el cual hace evidente su presencia en el Período Tardío. En Caspana se registran diferentes modalidades materiales de penetración incaica que seguramente coinciden con estrategias de dominio diversas. La primera de estas modalidades resulta exclusivamente incaica, por cuanto emplaza sus asentamientos en las inmediaciones de zonas productivas en términos de explotación minera y agroganadera. En dichos sitios (p.e., Cerro Verde, Incahuasi Inca y Vega Salada) se encuentran rasgos arquitectónicos altamente diagnósticos de su estilo (plataforma o ushnu, canchas o rectángulos perimetrales compuestos -conocidos como RPC-, bodegas y silos o collca), asociados a manifestaciones de arte rupestre, muchas veces también asignables al horizonte incaico. Paralelamente, se evidencia la influencia incaica en los asentamientos locales con una intensa ocupación previa como en el caso de la Aldea Talikuna, donde encontramos cerámica y algunos elementos arquitectónicos de esta filiación, obteniéndose fechas cercanas al 1450 DC en torreones tipo chullpa. Por último, la expansión también se registra en el Cementerio de Los Abuelos debido a la existencia de áreas acotadas de sepulturas con ofrendas de cerámica y metal que, a diferencia de los asentamientos locales, se ajustan completamente a los cánones cusqueños.

Por último, la localidad cuenta con ocupaciones arqueológicas hasta el Período Colonial Temprano, cuando se usan levemente algunos asentamientos previos como lo consignan otras fechas obtenidas para los sitios Aldea Talikuna y Estancia Chita. Durante estos momentos, se aprecia un debilitamiento de los núcleos de la población prehispánica con la consiguiente atomización de los sistemas estancieros. Sin duda, tal situación constituye un modo de vida que es paulatinamente desintegrado, el cual finalmente se traduce en las reducciones conocidas como "Pueblos de Indios", tal como ha quedado indicado en la documentación colonial de la localidad. En ella se reconocen sólo dos poblaciones importantes en la zona de estudio, correspondientes a los pueblos de Aiquina y Caspana, las cuales se encontraban representadas por un mismo curaca o autoridad indígena hacia 1622 (Manríquez 1999-2000). 


\section{El problema incaico en el Norte Grande de Chile}

Los diversos trabajos arqueológicos e históricos referidos a la problemática incaica en el actual territorio chileno expresan un modelo escasamente discutido que estigmatiza a la región comprendida entre Arica y el río Cachapoal como un área marginal de la expansión y dominio del Tawantinsuyu. La presencia del Imperio, de acuerdo a estas interpretaciones, estaría generalmente mediada por otras poblaciones. El origen de esta concepción se encuentra en los inicios de la arqueología como disciplina científica en nuestro país y marcarán decididamente las posteriores reflexiones en torno a esta temática (Uribe 1999).

Es responsabilidad del historiador Barros Arana, a través de su Historia de Chile, haber difundido la idea que el Imperio incaico habría introducido la civilización a estos territorios donde no habitarían más que una serie de poblaciones primitivas y bárbaras (Latcham 1928). Desde la arqueología, los trabajos pioneros de Latcham discuten la tesis de Barros Arana, sosteniendo, por el contrario, la existencia de importantes desarrollos culturales locales y minimizando el impacto que originalmente se le atribuía al Tawantinsuyu. La profunda herencia de Latcham en la disciplina influye en la sucesiva producción en torno a este problema desde los trabajos de Mostny $(1949,1971)$ hasta nuestros días, popularizando esta pobre imagen relativa a la influencia incaica en nuestro territorio. Se suma a lo anterior una visión errónea que utiliza como referente a los Andes Centrales, cuyas características como el monumentalismo de sus desarrollos culturales, opacan a los de más al sur (C. González 1996; Uribe 1999). Es en este marco, entonces, en el cual se elabora la literatura especializada sobre el problema.

En la década de 1970, la tesis de Llagostera (1976) marca un hito fundamental al evaluar la expansión incaica para la vertiente occidental de los Andes Meridionales, presentando una visión integral y aplicando los postulados sobre el control vertical de un máximo de pisos ecológicos de Murra (1975) a la zona referida. De este modo, el dominio incaico utilizaría una infraestructura archipielágica, representada por señoríos como los aymara, ya establecida antes del Imperio, donde algunas islas seguramente cobrarían más importancia que otras. Dentro de este marco, Llagostera sugiere igualmente una reconsideración de la posición del Horizonte Incaico y los desarrollos locales en los cuadros cronológicos (Períodos Intermedio Tardío y Tardío), viéndolos no de manera secuencial sino sincrónica. Este último aserto integró al discurso sobre el Período Tardío la necesaria complejidad de la dinámica social en territorios multiétnicos y, por ende, una crítica a la excesiva simplificación de las secuencias cronológicas vigentes.

Además del trabajo de Llagostera, algunos enfoques sintéticos de interés para abordar el tema en la localidad de estudio son los trabajos de Núñez y Dillehay (1995), así como la perspectiva histórica propuesta por Silva (1985). De acuerdo al modelo de movilidad giratoria (Núñez y Dillehay 1995), la expansión del Tawantinsuyu haría uso de la eficiente red de relaciones sociales, complementariedad económica y tráfico de caravanas existentes entre los señoríos de tierras altas y bajas, administrando inicialmente los ejes altiplánicos de mayor prestigio, ejerciendo un dominio "oblicuo" sobre los señoríos altiplánicos periféricos y propiamente transpuneños a través de los anteriores. Los incas optimizarían la explotación de recursos utilizados o desconocidos por las poblaciones locales y fomentarían el movimiento de bienes como una manera de integrar a éstas a su sistema.

Por otra parte, la síntesis general propuesta por Silva (1985) alude a la cronología de la expansión incaica en territorio chileno sugiriendo tres momentos, ocurriendo la incorporación del área que nos incumbe en el segundo de ellos, correspondiente al gobierno de Topa Inca Yupanque. En relación a la modalidad de incorporación de los territorios al Imperio, este historiador se apoya en la tesis de Llagostera para explicar la presencia incaica en el área de los valles tarapaqueños, mientras que para la zona atacameña sugiere una imposición por la fuerza que implicaría una conquista militar. Por otro lado, la presencia de arquitectura diagnóstica y otros artefactos han sido utilizados sistemáticamente para definir la presencia incaica. En este sentido, la síntesis desarrollada por Raffino (1981), quien a partir de un análisis exhaustivo del registro arqueológico define los rasgos infraestructurales de primer, segundo y tercer orden, y los rasgos mobiliares que se presentan en diferentes combinaciones en los asentamientos bajo la esfera del Tawantinsuyu descritos en su 
trabajo, constituye un aporte básico que ofrece la posibilidad de hacer comparaciones, y es de gran utilidad para la investigación en terreno. En otro plano, sostiene que aquí es "relevante la recurrencia, cuali y cuantitativa entre las pruebas arqueológicas, específicamente de la infraestructura imperial, y los vestigios de explotaciones mineras" (Raffino 1981: 248). Tal situación es del todo compatible con el registro arqueológico de la localidad de Caspana, donde tres de las instalaciones reconocidas como incaicas se encuentran directamente asociadas a fuentes de extracción de minerales.

De este modo, los modelos de complementariedad ecológica vertical, de caravanas comerciales, la fuerza militar o la acumulación de metales, han sido los argumentos más populares que se han esgrimido para tratar el problema del Inka en Chile, en especial, del Norte Grande. Así, por ejemplo, la presencia del Tawantinsuyu en la sierra de Arica se evalúa acogiendo los postulados de Llagostera (1976), afirmándose que el norte de Chile sería incanizado vía poblaciones altiplánicas (Muñoz y Chacama 1993). Los asentamientos bajo la esfera de dominio del Tawantinsuyu, en gran parte concentrados en la sierra, permitirían, por lo tanto, ejercer el control sobre importantes recursos económicos locales, el movimiento de bienes, como también controlar las rutas del tráfico costa-altiplano.

Más al sur, en los oasis de San Pedro de Atacama, la presencia incaica ha sido tratada por numerosos investigadores a lo largo del tiempo (Latcham 1928; Mostny 1971; L. Núñez 1992; P. Núñez 1993). Según Núñez (1992), el dominio incaico de este territorio se habría hecho efectivo durante la Fase Solor con un carácter oblicuo, por cuanto no llegarían directamente desde el Cusco, sino desde sus centros administrativos del altiplano: "No ejercen un dominio militar y cultural directo, ya que no se aprecian conflictos militares ni la imposición de un modelo cultural" (Núñez 1992: 73). En este sentido, la ocupación incaica enfatizaría una estrategia política más que cultural, fundamentándose en alianzas con las autoridades atacameñas. El interés del Imperio, para este investigador, lo constituiría el tráfico interregional hacia los centros administrativos del altiplano, donde la producción aumenta en escala, optimizando la generación de excedentes y la circulación de bienes para la reproducción del Estado cusqueño.
Para esta misma zona, la cuenca del río Loa contiene una importante serie de registros de asentamientos del Tawantinsuyu, mencionados en la literatura especializada de diferentes épocas, notándose su presencia en casi todos los tramos, así como en las subregiones Río San Pedro y Río Salado (Castro 1992). En esta última, los trabajos iniciados en el Pucara de Turi han dado lugar a diversos trabajos que abordan el tema de la ocupación incaica en las tierras altas del Loa, de los cuales sólo mencionaremos algunos como ejemplos interesantes.

Aldunate (1993) ha postulado tres fases arqueológicas que sistematizan la constante ocupación del asentamiento durante el Período Intermedio Tardío. De acuerdo a ello, la Fase Turi 2 (13501550 DC) daría cuenta del "contacto entre la Fase Turi 1 y la Tradición Altiplánica o Fase Toconce, que en esta época habría ocupado la zona de quebradas intermedias de la cuenca del río Salado. Durante esta misma fase se advierte claramente la presencia del Tawantinsuyu, llegada tempranamente a través de la Tradición Altiplánica (Aldunate 1993: 61). Por su parte, Cornejo (1995) ofrece una síntesis interpretativa, integrando toda la región del Loa Superior y el problema de la relación entre lo local y lo foráneo. Plantea una ocupación del espacio por parte de los incas, diferente a la de la población local y a la del Tawantinsuyu en otras regiones, determinada por los intereses estatales en este sector: por un lado, el aprovechamiento de los recursos mineros y, por otro, el control de la ruta hacia el sur. En esta región y obedeciendo a una clara planificación, la ocupación incaica tomaría la forma de una delgada línea cubriendo un área sobre los 3000 m.snm en un eje norte-sur, por lo cual quedarían bajo su esfera una porción de sitios sobre los márgenes del río Loa, y otra en puntos estratégicos de las quebradas altas tributarias del mismo. Además, señala que no sería necesaria una presencia masiva de población para sostener la ocupación del espacio, lo que evidentemente requeriría de otros mecanismos de dominación entre los que se privilegia la arquitectura como una señal de apropiación del espacio local.

En esta dirección, la presencia de arquitectura incaica en el Pucara de Turi ha permitido a Gallardo y colaboradores (1995) profundizar sobre la naturaleza del dominio incaico sobre las poblaciones locales de la región. Consideran la presen- 
cia de su arquitectura como expresión política, en cuanto se entiende que el asentamiento exhibe:

"un amplio conjunto de diferencias constructivas y estilísticas -locales y foráneas-que suponemos son la expresión de una tensión social, de una interrelación cultural que manifiesta el ejercicio de un poder de dominación por parte del Inka" (Gallardo et al. 1995: 151).

Basándose en el registro arqueológico y en información etnohistórica, identifican un conjunto de relaciones que manifestarían decisiones culturales, organizando una trama espacial de actos significantes para la estrategia de apropiación incaica. Según los autores, la arquitectura incaica presente en el pucara sugiere que:

"tal acto material representaba una apropiación del espacio a resguardo de un concepto fundacional de causalidad andino (tecci), una categoría cuya expresión arqueológica tendría relación con la presencia de cimientos en los recintos incaicos o callancahuasi. Este conjunto de evidencias indicaría que el Inka materializa su poder de dominación edificando sobre un espacio construido, estableciendo un nuevo orden al amparo de un acto de refundación cultural que ideológicamente enmarca al "otro" dentro de su propia historia.

[El Inka] establece una vecindad con lo local, pero al mismo tiempo despliega un conjunto de diferencias que imponen una distancia respecto al entorno material que le rodea [...] para legitimar su dominio en lo social el Inka debe establecer una hegemonía sobre lo sagrado, sobre aquellos espacios destinados al ritual por los habitantes del pucara" (Gallardo et al. 1995: 169).

\section{Caspana en la esfera del Tawantinsuyu}

Las investigaciones en Caspana nos permitieron distinguir una distribución diferencial de los yacimientos arqueológicos del Período Tardío (Figura 2). Estas, en un primer momento, nos presentaron las siguientes categorías de sitios, gracias a las cuales comenzamos nuestra reflexión sobre la ocupación incaica y cuya caracterización profundizamos en esta ocasión:

1) Sitios definibles como aldeas de la población local, los cuales combinan elementos de las tradi- ciones del Desierto y Altiplánica (Schiappacasse et al. 1989). Son de distinta envergadura, se encuentran dentro de la gradiente altitudinal por sobre los $3000 \mathrm{~m} . \mathrm{snm}$, asociados a la explotación de sus recursos agrícolas y ganaderos. En ellos apenas se registran algunos fragmentos cerámicos y ciertos rasgos arquitectónicos asignables al Horizonte Incaico.

2) Por otra parte, sitios con una indiscutible arquitectura incaica, alejados de los poblados locales y en directa asociación con espacios de explotación minera y agrícola. La alfarería exhibe componentes heterogéneos donde se combinan cerámica local, foránea y propiamente incaica (Yavi, Gentilar y otros), se reconocen manifestaciones de arte rupestre de camélidos lineales rígidos y están conectados por un Camino del Inka, compuesto por redes viales en un eje norte-sur y otras menores en sentido este-oeste.

3) Finalmente, sitios donde se expresan abiertamente elementos locales, foráneos e incaicos dentro de un contexto cerrado, pero "trascendente" como es el funerario. Este es el caso del Cementerio de Los Abuelos donde las ofrendas de ciertas tumbas, entre otros artefactos, presentan cerámica local, de influencia altiplánica, inca local, inca foránea y/o quizás cusqueña. Lo anterior definiría a este espacio como un lugar privilegiado de encuentro de distintas manifestaciones culturales, dando cuenta de una situación donde se acepta la expresión de las diferencias.

\section{Los asentamientos de la población local}

El primero de éstos es la Aldea Talikuna ${ }^{5}$ que se ubica sobre el talud de la ladera sur de la quebrada homónima, al nororiente del río Caspana, en las coordenadas geográficas $22^{\circ} 19^{\prime}$ Lat. Sur y $68^{\circ}$ $12^{\prime}$ Long. Oeste. Los fechados absolutos que hemos obtenido indican que se encuentra ocupado durante los períodos Intermedio Tardío y Tardío: 1305 DC (UCTL 723; 690 \pm 70 AP), 1465 DC (UCTL 724; 530 \pm 60 AP) y 1608 DC (UCTL 722; $835 \pm 90 \mathrm{AP})$.

En términos generales, este asentamiento se ha descrito como una aldea en ladera (ver plano en

\footnotetext{
Previo a nuestros trabajos, este asentamiento ha sido estudiado por diversos investigadores, entre los cuales destacan Le Paige (1958), Núñez (1965) y Barón (1979).
} 


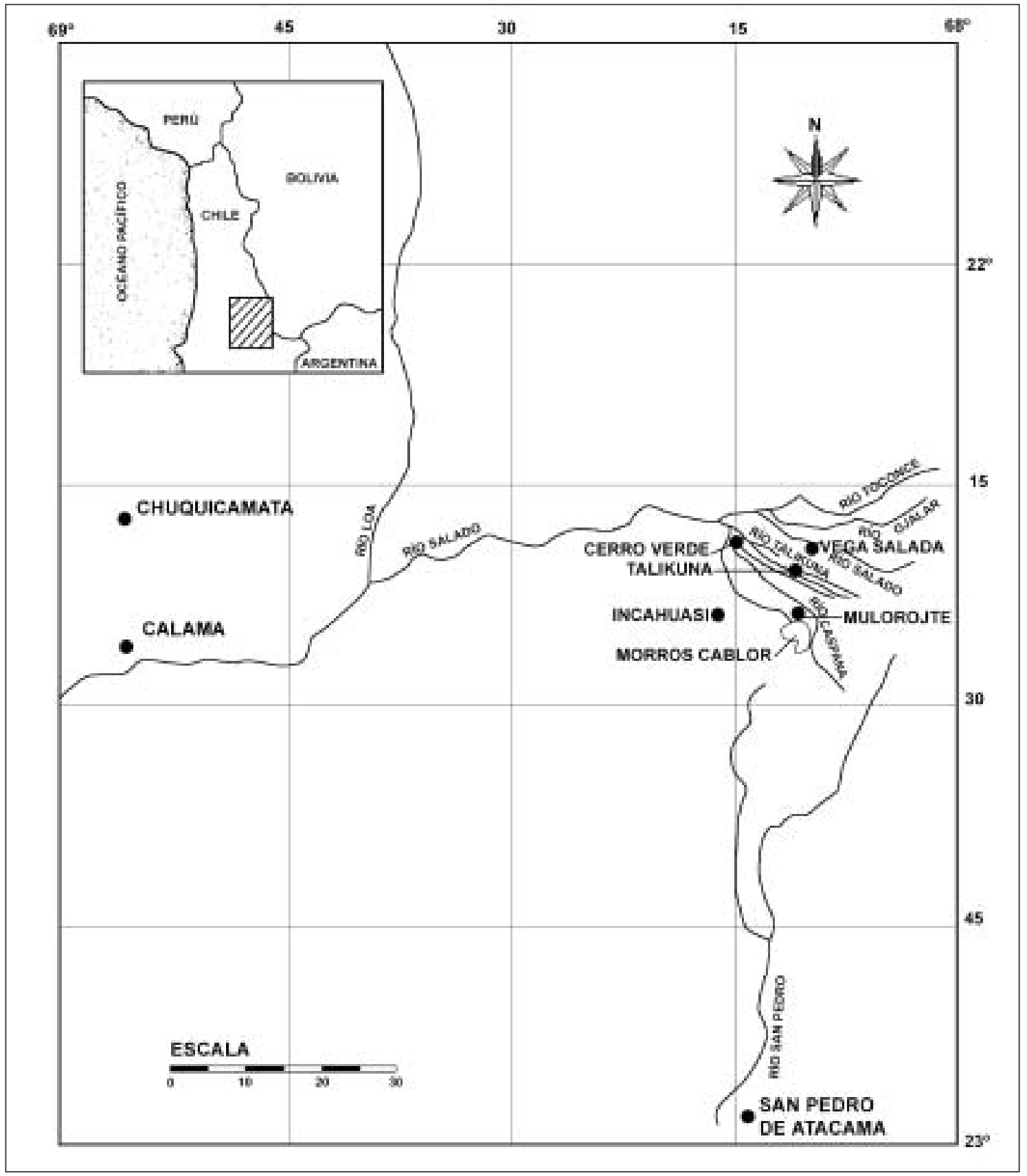

Figura 2. Mapa de la localidad de Caspana con los sitios mencionados en el texto.

Adán 1999: Fig. 2) compuesta por tres sectores edificados (Le Paige 1958; Adán et al. 1995; Adán 1999; Ayala 2000a, y 2000b). En su parte inferior se distingue un sector agrícola, caracterizado por un complejo sistema de terrazas de cultivo o andenes, que se extiende ampliamente mucho más allá, aguas arriba y abajo, de la aldea. Este sistema se encuentra cruzado por una serie de canales longitudinales y transversales que dan cuenta de un importante conocimiento agrohidraúlico. Inmediatamente sobre dicho sector, se ubica el área residencial, separada de la agrícola por el canal principal que corre bajo las primeras estructuras. En una primera observación, destacamos la existencia de conjuntos arquitectónicos de planta rectangular, los cuales podrían corresponder a espa- 


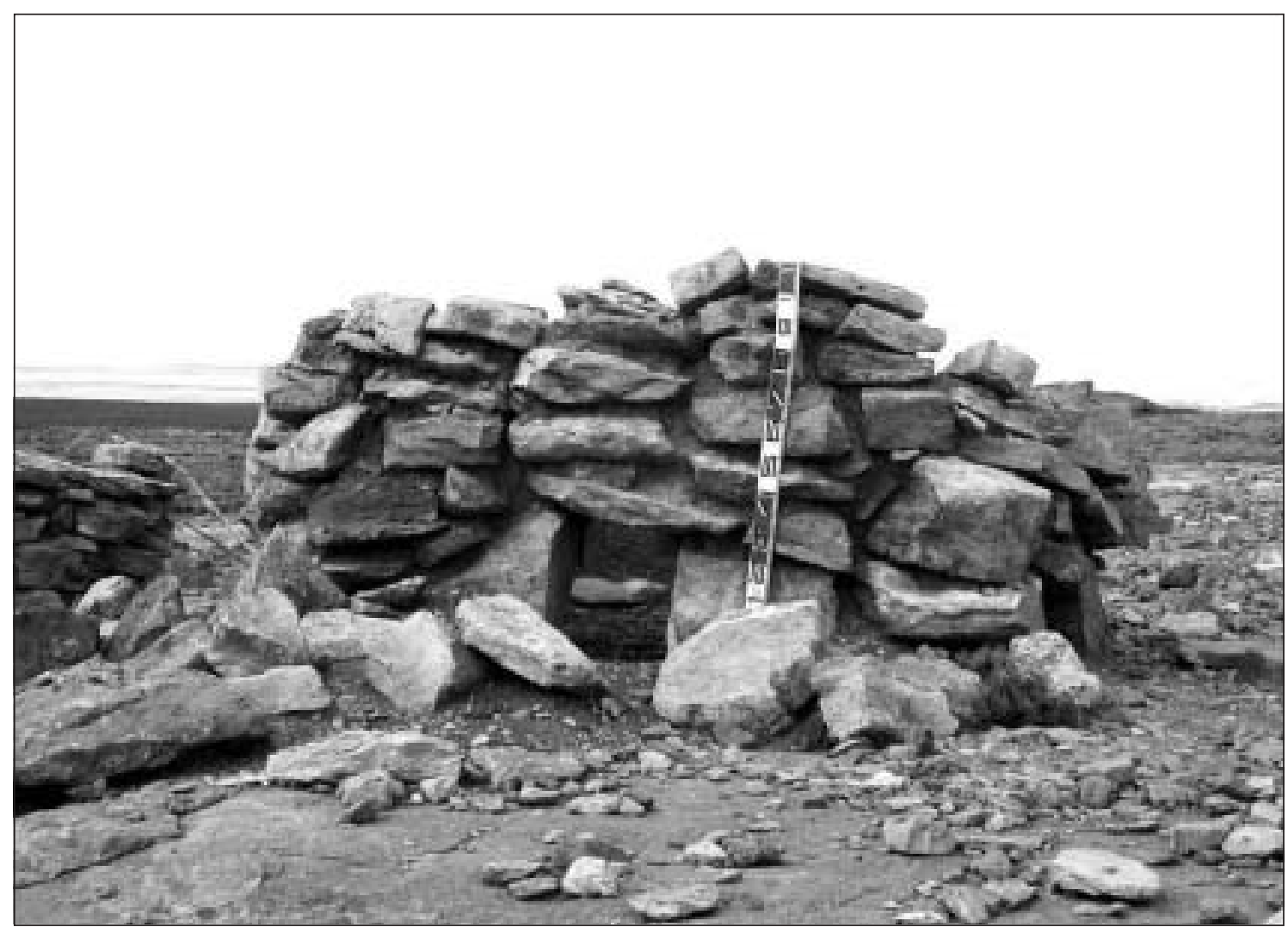

Figura 3. Estructura tipo chullpa.

cios domésticos, y un segundo tipo de estructuras de patrón constructivo tipo chullpa (Figura 3), usadas como adoratorios, bodegas e incluso sepulturas (Aldunate y Castro 1981; Ayala 2000a y 2000b). ${ }^{6}$ Por último, en la parte más alta se identificaron construcciones parecidas a éstas, pero adosadas a grandes bloques rocosos del mismo modo que en el Cementerio de Los Abuelos, las cuales corresponderían a enterramientos y también a bodegas.

Hoy sabemos que Talikuna se compone de 151 estructuras arquitectónicas pircadas, en las que

6 El registro de este tipo de estructuras efectuado por Ayala (2000a y 2000b) indicó que se trataría de 18 estructuras con una altura promedio de 90 a $185 \mathrm{~cm}$, con plantas de forma circular, elipsoidal y rectangular, algunas de estas últimas dobles. Respecto del emplantillado se logra mediante el uso de piedras planas, redondeadas, o bien, usando la roca madre como piso. Los vanos presentan diferentes orientaciones aunque predominan aquellas cuyas aberturas miran al sureste. predomina la planta rectangular y subrectangular, de trazado irregular. Las superficies oscilan entre los $1.69 \mathrm{~m}^{2}$ hasta los $88.66 \mathrm{~m}^{2}$, concentrándose entre los $7.50 \mathrm{~m}^{2}$ y los $38 \mathrm{~m}^{2}$. Funcionalmente, estas construcciones corresponderían, entre otros, a recintos habitacionales, espacios entre-recintos, aterrazamientos, bodegas, estructuras tipo chullpa y corrales. En cuanto al problema incaico, algunos rasgos arquitectónicos de interés son las hornacinas, puertas con dintel de piedra, escaleras, poyos y lajas alineadas enterradas a modo de cajas. Sin embargo, destaca la ausencia de muro perimetral (Adán 1999).

Al igual que en otros asentamientos contemporáneos de la localidad, así como de la mayor parte del mundo andino, en Talikuna, a diferencia de la arquitectura incaica, se nota un crecimiento espontáneo, sin una planificación inicial total, como hoy se ocupan los poblados locales (Agurto 1987). No obstante, lo anterior no significa que no existan conocimientos especializados comprometidos en su construcción. Como hemos señalado, el 
hacer habitable esta quebrada y, en general, las quebradas altas de la región, requiere de conocimientos y tecnologías adecuadas que en algunos instantes debió demandar especialistas. Talikuna, en definitiva, se trata de un sitio de dimensiones regulares formado por cinco conglomerados arquitectónicos, compuestos a su vez por diversas unidades domésticas, lo que es necesario percibir desde una perspectiva diacrónica (Adán 1999).

En una primera etapa, ${ }^{7}$ se excavaron seis estructuras de planta rectangular y tres recintos subcirculares o de patrón constructivo tipo chullpa. Este material nos aportó una primera impresión a la distribución de la alfarería (Ayala 2000a). Una aproximación general al material recuperado indicó un claro predominio del tipo Turi Rojo Alisado y su variante funcional Gris Alisado, pues juntos representan un $67 \%$ de la muestra. Les siguen en proporción los platos o escudillas del tipo Aiquina con el $15.5 \%$ y las Dupont con un 5\%. Bajo este porcentaje aparecen el tipo Turi Rojo Burdo y el Café Alisado bordeando el 1\%, los tipos altiplánicos como Hedionda, Yavi u otros no sobrepasan el $0.5 \%$, como tampoco los Revestidos Rojos de Turi. ${ }^{8}$

Posteriormente, en una segunda temporada, se realizó un muestreo al azar de un $20 \%$ de las unidades del sitio seleccionándose 17 estructuras, las que fueron recolectadas en superficie. El comportamiento tipológico confirma y enriquece los resultados que obtuvimos con anterioridad. En Talikuna se encuentran representados 19 grupos cerámicos que nos permiten afirmar un predominio casi exclusivo del componente alfarero LoaSan Pedro (Figura 4), con vasijas de tamaño considerable y formas restringidas simples como complejas, pertenecientes al tipo Turi Rojo Alisado (sobre el $33 \%$ de la muestra) ${ }^{9}$, acompañadas por piezas más pequeñas y no restringidas del tipo Aiquina (sobre el 23\%). Por lo tanto, las principales funciones representadas en el sitio son de carácter doméstico, relacionadas directamente con la preparación, conservación, almacenamiento y

7 Proyecto FONDECYT 1940097.

8 La tipología cerámica que se utiliza en este trabajo tiene como base los trabajos de Varela (1992) en el Pucara de Turi. Para mayores antecedentes vea Varela y colaboradores (1993).

9 En este grupo cerámico se reconocen cuencos o fuentes, jarros, ollas y, especialmente, cántaros. servicio de alimentos sólidos y líquidos (Uribe y Carrasco 1999). El resto del material cerámico se distribuye dentro de una gran variedad tipológica que, si bien puede analogarse a los tipos anteriores en términos morfofuncionales, tienen connotaciones temporales, culturales y simbólicas particulares. En el rango 5-10\% se encuentran los tipos Turi Rojo Burdo y Rojo Revestido Alisado del componente Loa-San Pedro. En cambio, en el rango 0-5\% aparece una mayor variedad tipológica donde se reconocen los tipos Hedionda, Yavi y expresiones locales del componente altiplánico, el resto de la cerámica Loa-San Pedro como los tipos Turi Gris Alisado, Dupont, Turi Rojo Pulido, San Pedro Rojo Violáceo y el inca local Turi Rojo Revestido Exterior-Negro Alisado Interior y, por último, aquellos del componente protoetnográfico de Turi y Lasana (Uribe y Carrasco 1999).

Prácticamente no se detectó material lítico en superficie, excepto por restos de mineral de cobre y una importante cantidad y variedad de artefactos de molienda (p.e., manos, morteros, tacitas), que por su considerable envergadura aún se encuentran in situ y no han sido analizados con rigurosidad.

Por otra parte, en el poblado se registraron seis paneles o unidades de relevamiento de arte rupestre. Ellos se ubican al interior de la parte central de la aldea y corresponden a grabados realizados en bloques menores de piedra que forman parte de los muros de algunos recintos $\mathrm{y}$, en el menor de los casos, sobre rocas móviles hoy emplazadas en algunas vías de circulación. Los grabados corresponden a representaciones en su mayoría ejecutadas por percusión y sustracción profunda del soporte rocoso. En uno de los bloques se reconoció una horadación muy profunda con agujeros más pequeños a su alrededor, dispuestos de manera no aleatoria. Los paneles restantes presentan líneas verticales o ligeramente curvas de surco delgado y hondo (Vilches y Uribe 1999). Este arte rupestre de Talikuna, bastante escaso, se asemeja a algunas variedades definidas para el Pucara de Turi y a algunas otras variantes del mismo que fueron sistematizadas con posterioridad (Gallardo y Vilches 1995). ${ }^{10}$

10 La ausencia de correlatos iconográficos para estas figuras, fue la razón por la que ellos se marginaron de la tipología confeccionada para el Pucara de Turi (Gallardo y Vilches 1995). 

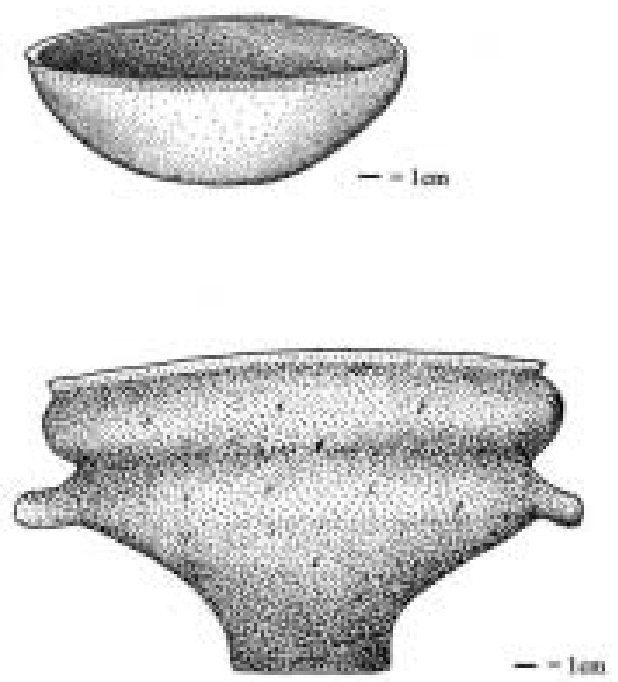

$-\infty$ les
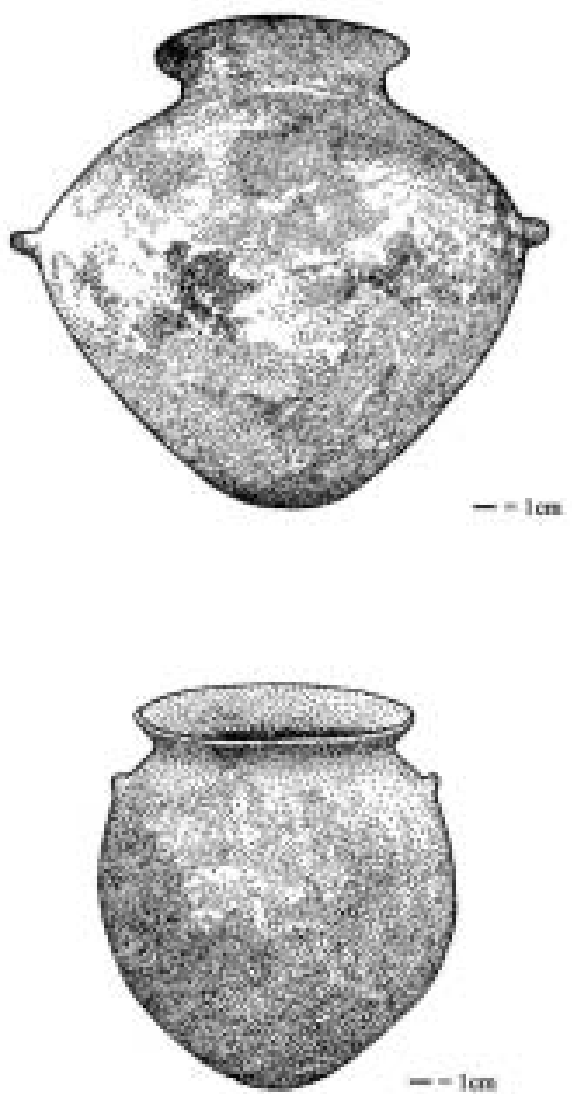
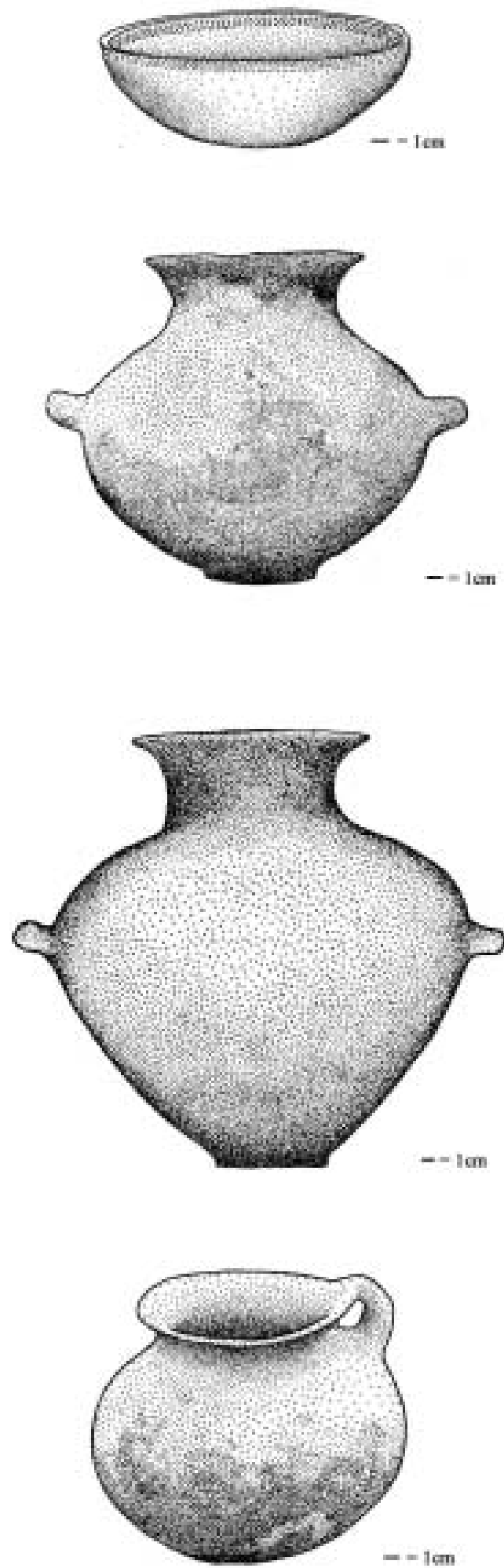

Figura 4. Componente cerámico Loa-San Pedro. 
Un segundo asentamiento de esta primera categoría de sitios (ocupaciones locales con tenue presencia de materiales diagnósticos del Tawantinsuyu) es la Estancia Mulorojte. Ella corresponde a otro sitio en ladera (ver plano en Adán 1999: Fig. 3), formado por conjuntos aglutinados de 66 estructuras arquitectónicas, pero de una envergadura menor a la de Talikuna, lo que nos sugiere una densidad ocupacional también menor, con probabilidad estacional, como ocurre en las estancias actuales. La única datación es de 1240 DC (UCTL $725 ; 755 \pm 80$ AP), confirmando su ocupación durante el Intermedio Tardío y su pertenencia a las poblaciones locales de esa época.

El yacimiento se ubica en los faldeos nororientales de los Morros de Cablor, en las coordenadas geográficas $22^{\circ} 23^{\prime}$ Lat. Sur y $68^{\circ} 9^{\prime}$ Long. Oeste, aprovechando un pequeño anfiteatro donde se origina la quebrada de Mulorojte y a una altura de $3800 \mathrm{~m} . \mathrm{snm}$. A $3 \mathrm{~km}$ se encuentran las vegas del Cablor, a una distancia similar las vegas de Chita y la laguna de Coyer, correspondiente al principal tributario del río Caspana. Por lo tanto, el lugar en que se construyó Mulorojte se asocia a espacios de importancia para la ganadería de altura, producto de su potencial forrajero que hasta hoy mantiene sistemas estancieros; pero, además, susceptibles de ser explotados estacionalmente en términos agrícolas (p.e., papa y quinoa). En este sentido, hemos sugerido que la Estancia Mulorojte se relaciona con actividades de pastoreo, considerando su cercanía a las vegas, y a alguna agricultura de secano, a juzgar por los fragmentos de pala y morteros encontrados en superficie. Cercano al sitio se han identificado campos pircados que podrían haber sido usados como corrales o trampas para animales y también para algún cultivo resistente a la altura que no requiriera de riego artificial. También es sugerente pensar en la asociación del sitio con los Morros de Cablor en cuanto cerros tutelares o divinidades locales, tal cual son reconocidos por la comunidad indígena en la actualidad, pues el yacimiento constituye una suerte de parada obligada en el ascenso a su cima, donde se realizan ceremonias vinculadas al agua y la tierra. ${ }^{11}$

11 Una de las actuales rutas de ascenso a la cima del Cablor, de acuerdo a información etnográfica recabada en la localidad de Caspana, es por este sector.
Al igual que Talikuna, Mulorojte se encuentra edificado sobre un gran sistema de aterrazamientos en el cual se observan estructuras de planta rectangular, de tamaños variables y muros de hilada simple. Además, también hay algunas construcciones de planta subcircular que, arquitectónicamente, evocan a las estructuras tipo chullpa. El espacio se organiza en tres sectores (Adán 1999). El primero de ellos, corresponde al sector bajo, cortado en la actualidad por un camino de vehículos. En él dominan las estructuras de grandes dimensiones a modo de corrales con recintos menores adosados que, en algunos casos, parecen ser habitaciones y, en otros, "chiqueros". ${ }^{12}$ Algunos rasgos tardíos interesantes en la parte baja del asentamiento, son una habitación con hornacina, otras con poyos, "cajitas" en los pisos y, aunque predominantemente simples y rústicos, algunos muros dobles. Tal como se observa la organización de este sector hoy en día, el sitio parece ser la expresión de diversos eventos constructivos con sucesivas modificaciones en sus edificaciones. El segundo sector se encuentra sobre el anterior, formado por cuatro niveles de aterrazamiento donde también se observa el patrón que asocia un recinto de pequeñas dimensiones de planta subrectangular con una estructura mucho mayor e irregular a modo de corral. Sin duda, es la continuación del sector bajo, formando otra unidad de manera muy parecida al sistema constructivo de las estancias actuales.

Por último, hemos reconocido un sector oriental alto bastante confuso, formado por un conjunto de edificaciones que escapan a los recintos que hemos definido más arriba, pudiéndose reconocer sólo un pequeño conjunto de estructuras tipo chullpa en la cima, y varios aterrazamientos en distintas partes.

En relación a la alfarería, las primeras excavaciones practicadas en los tres sectores del sitio indican, en términos generales, un predominio del tipo Turi Rojo Alisado con un $42 \%$, seguido por un $14.8 \%$ de escudillas Aiquina y luego de las ollas Turi Gris Alisado con un 11.6\%. Por su parte, el tipo Dupont sólo implica un 3.6\% de la muestra, mientras la cerámica altiplánica y los

\footnotetext{
12 Con el término "chiquero" se designan pequeñas estructuras adosadas a corrales mayores, cuya finalidad es servir de refugio a hembras parturientas y a los animalitos pequeños.
} 
revestidos rojos obtuvieron porcentajes menores al $1 \%$. Sin embargo, es considerable la representación que tiene el tipo Turi Rojo Revestido Exterior-Negro Alisado Interior (alrededor del 8.5\%), confirmándonos que el asentamiento fue parte del Tawantinsuyu, debido a las formas "aribaloides" de esta cerámica y un fechado de 1650 DC del Pucara de Turi (Varela et al. 1993). Por su parte, la recolección superficial de un $20 \%$ de las estructuras del sitio reafirma esta situación, pues se observa el predominio del componente Loa-San Pedro. En particular, otra vez se identificó la presencia de los tipos Turi Rojo Alisado, Rojo Burdo, Aiquina, Turi Gris Alisado, Dupont, Turi Rojo Revestido Pulido, Rojo Revestido Exterior, San Pedro Rojo Violáceo y Rojo Revestido ExteriorNegro Alisado Interior, pero, en esta ocasión, no se registraron ejemplares altiplánicos del suroeste boliviano ni de la puna argentina; en cambio, sí fragmentos cerámicos del componente temprano, formados por tipos característicos del Formativo Tardío de la zona (Sinclaire et al. 2000).

Por su parte, el material lítico de Mulorojte indica que las categorías de artefactos más representadas aquí son las lascas secundarias, sin retoque, las palas líticas y las lascas primarias. En su conjunto, éstas denotan una tendencia a las actividades de talla de carácter secundario, sin dejar de considerar las posibles labores agrícolas donde pudieron funcionar las palas (Uribe y Carrasco 1999). Las materias primas más populares son, respectivamente, el basalto y la andesita, parte del primero correspondiente a manifestaciones tempranas, previas a la ocupación del Intermedio Tardío, como también lo sugiere la alfarería.

A diferencia de Talikuna, no se registró arte rupestre en la Estancia Mulorojte ni en sus inmediaciones.

En suma, los dos sitios descritos indican una modalidad característica de las poblaciones locales del Período Intermedio Tardío por ocupar complementariamente diferentes espacios ecológicos, con asentamientos de una complejidad arquitectónica funcional a las actividades domésticas tradicionales (habitacional, agrícola, ganadera), y un registro alfarero que les otorga una identidad propia, pero no exenta de importantes relaciones interculturales. Igualmente, en ambos casos es evidente el componente tardío a través de escasos pero diagnósticos tipos alfareros asigna- bles al Horizonte Incaico, bastante recurrentes en las estructuras tipo chullpa, aún no valoradas en relación a su información sobre el período en cuestión.

\section{Las instalaciones incaicas}

En el segundo conjunto de sitios estudiados, se encuentran Cerro Verde, Incahuasi Inca y Vega Salada, los cuales comparten con los anteriores la presencia de alfarería local, no obstante, se diferencian radicalmente por presentar una construcción del espacio propia del Tawantinsuyu.

El yacimiento de Cerro Verde se localiza en una explanada del cerro homónimo, ubicado en la confluencia de los ríos Curte y Caspana, a una altura de $3140 \mathrm{~m} . \mathrm{snm}$ y en las coordenadas geográficas $22^{\circ} 18^{\prime}$ Lat. Sur y $68^{\circ} 14^{\prime}$ Long. Oeste. ${ }^{13}$

Se trata de un asentamiento que comprende tres sectores de edificación (ver plano en Adán 1999: Fig. 4), en los que se distinguen 55 estructuras organizadas en un trazado ortogonal, mayoritariamente de planta rectangular, cuyas superficies se concentran entre los $3.96 \mathrm{~m}^{2}$ y $26.98 \mathrm{~m}^{2}$. El primero de estos tres sectores se define como alto, pues se localiza sobre un promontorio rocoso donde se levanta una construcción piramidal de piedra canteada o ushnu, asociado a un recinto habitacional amurallado. El ushnu presenta dos niveles superpuestos, posee pequeñas escaleras en dos de sus costados; se utilizó argamasa en su construcción y, como otras estructuras del sitio, se enlució con barro (Figura 5).

El recinto habitacional, por su parte, es de planta rectangular, con doble muro y subdivisiones en su interior. Sus paramentos también poseían el característico revoque de barro. El segundo sector, $20 \mathrm{~m}$ más abajo del anterior, comprende un sistema de rectángulos perimetrales compuestos (RPC), es decir, recintos rectangulares que forman un patio central dentro de un esquema de patrón en "U". El primer conjunto al que se accede tiene muros simples de laja. Unos 40 m más arriba de este conjunto, hay estructuras en forma de "L", de doble muro con relleno de piedrecillas

\footnotetext{
13 Debido al sistemático saqueo del sitio, no hemos realizado dataciones hasta no contar con contextos más seguros que los superficiales.
} 


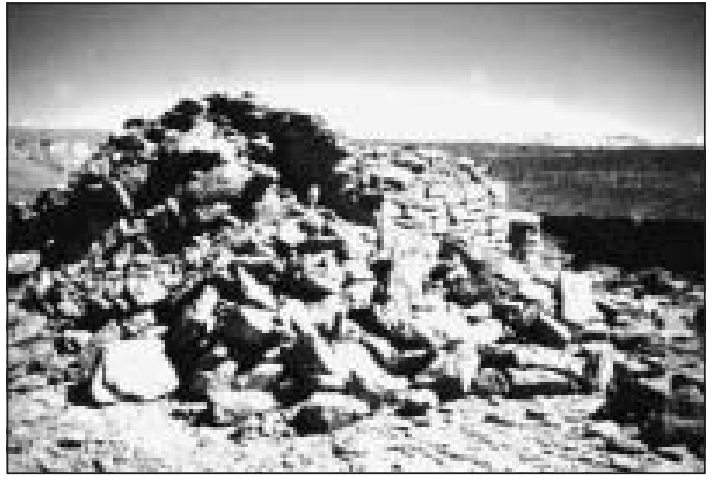

Figura 5. Ushnu de Cerro Verde.

y bastante derrumbadas (Castro 1992). Finalmente, al oriente del sector recién mencionado, fuera de los muros que delimitan lo que parece ser la parte central, se ubica un conjunto de 15 recintos de planta rectangular donde también se distinguen algunos RPC. En esta área, Silva (1979 Ms) registró evidencias de fogones y gran cantidad de huesos calcinados, fragmentos de cerámica y un mortero, lo que sugiere una ocupación más permanente que la de otros sectores.

Cerro Verde, a diferencia de los asentamientos locales mencionados, fue construido en un lugar plano, por lo cual no fue difícil reproducir el trazado ortogonal que caracteriza a las edificaciones incaicas (Adán 1999). Además de ser plano, éste es un terreno lo suficientemente alto como para observar desde aquí el entorno que le rodea, como la vega del Pucara de Turi y los cerros y volcanes próximos y, por otra parte, también para ser visto desde distancias lejanas. Todo esto sumado a las características de los muros, las formas de plantas y la disposición de los espacios entre-recintos nos enfrenta a una concepción muy distinta a la preexistente. Por todo ello, su construcción evidencia la participación de especialistas que conocen a cabalidad la arquitectura e ingeniería propias del Tawantinsuyu, cuya organización ilustra lo que Agurto (1987) ha llamado urbanismo planificado. Esto, sin duda, se relaciona con la ubicación del sitio funcionalmente asociado a áreas de explotación de mineral de cobre y a los espacios agrícolas de Caspana, pese a que en lo inmediato no se encuentran terrazas de cultivo. Por último, es también relevante su conexión con uno de los principales ramales del camino imperial o inkañam, el cual a su vez lo hace con el Pucara de Turi e Incahuasi Inca (Varela 1999).
Unos $150 \mathrm{~m}$ al sur del sector oriental de Cerro Verde se han registrado manifestaciones de arte rupestre, configurándose éste en otra de las principales características del lugar. Ellas se localizan en un pequeño afloramiento rocoso aislado, que alberga tres paneles con representaciones de camélidos lineales rígidos, grabados en su totalidad, análogos a los tipos definidos para Turi (Gallardo y Vilches 1995), los cuales fueron construidos con líneas simples y/o por raspados de superficies mayores (Vilches y Uribe 1999). Algunos de éstos, no obstante, presentan pintura ocre rellenando áreas raspadas y están acompañados de otras figuras donde se distinguen un círculo y cuadrúpedos de cuerpo relleno o lineal no determinados (Vilches y Uribe 1999). Aproximadamente $50 \mathrm{~m}$ al sur de dichos paneles, se ubica un pique minero con una serie de socavones (sitio 02CAS/CUR-12). ${ }^{14}$ En uno de ellos, se registró una pintura que corresponde a una cruz concéntrica ejecutada en tres colores, blanco, negro y rojo, y un camélido más bien rígido en pintura blanca. Bajo la capa de hollín que cubre las paredes de este socavón se distinguen restos de más pinturas, pero cuyas formas son indeterminables. Siguiendo hacia el sur, en la confluencia de una quebrada seca con el río Curte, se ubica el sitio El Mirador con estructuras de características habitacionales, de planta rectangular y algunas estructuras de patrón constructivo tipo chullpa. Aquí se registraron cuatro paneles, tres de los cuales repiten la presencia de camélidos lineales rígidos de cuerpo raspado y en un caso pintado de color rojo. Por último, en la ladera este de la quebrada seca al oriente de Cerro Verde (sitio 02-CAS/CUR-11) existen tres paneles ejecutados en la pared rocosa, en los cuales se observan superposiciones estilísticas que combinan diseños geométricos, camélidos naturalistas de grandes dimensiones y pequeños camélidos rígidos (Adán 1996 Ms).

El análisis de la escasa alfarería que se logró recolectar en Cerro Verde mantiene un predominio del componente Loa-San Pedro, representado por los tipos Turi Rojo Alisado, Rojo Burdo, Aiquina,

\footnotetext{
14 La identificación del sitio incluye un primer código que representa a la región administrativa del país; el segundo a la localidad, en este caso Caspana; el tercer código, la denominación del sector donde se encuentra el sitio como las quebradas y, el último, corresponde a un número correlativo de los sitios identificados de norte a sur y de oeste a este dentro del área prospectada (Adán 1996 Ms).
} 


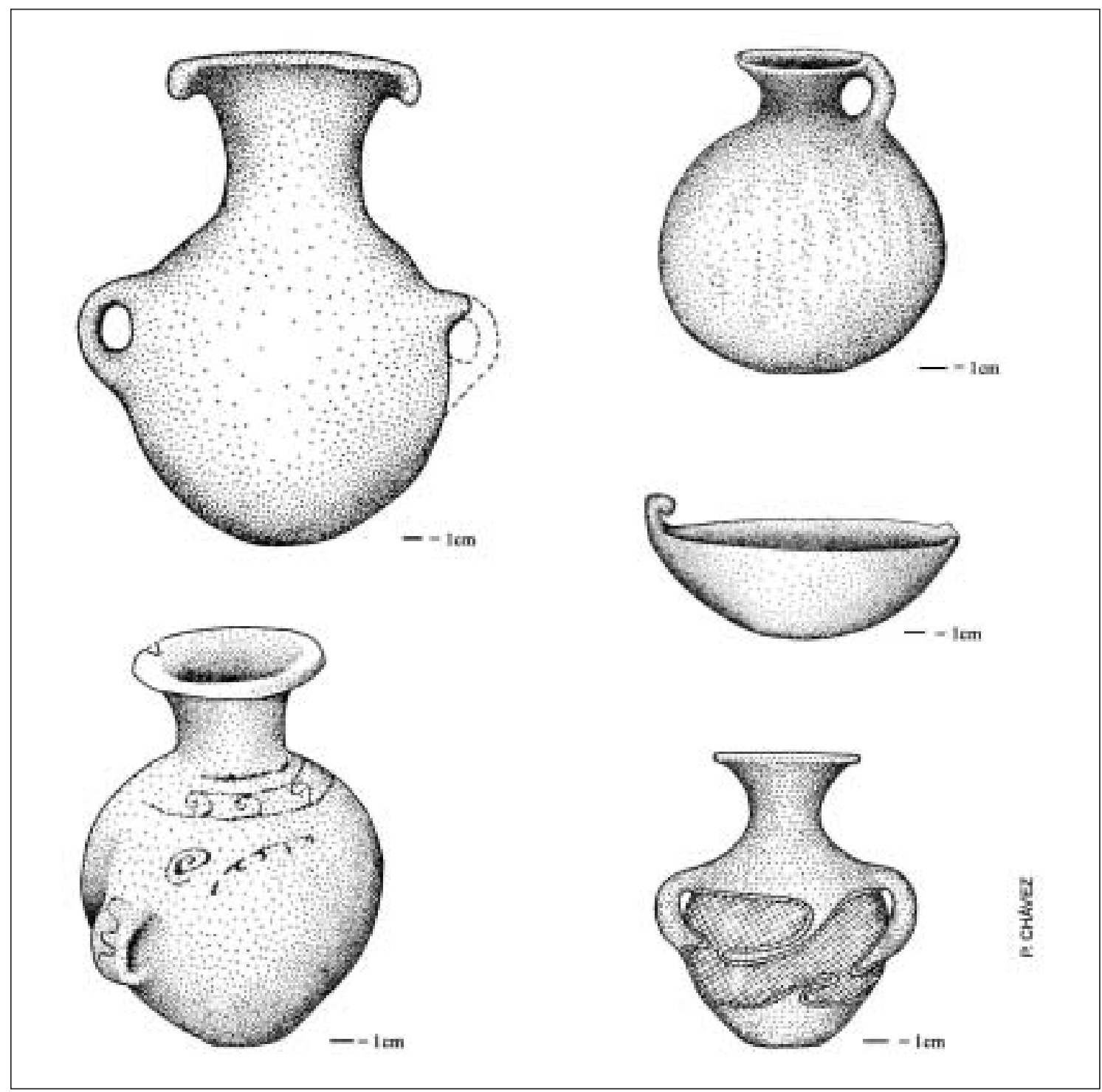

Figura 6. Componente cerámico incaico.

Turi Gris Alisado, Rojo Revestido Pulido y Rojo Revestido Exterior (Uribe y Carrasco 1999). Además, se registraron claros ejemplos locales del componente incaico, correspondientes a los platos con adornos ornitomorfos del tipo Turi Rojo Revestido Pulido Ambas Caras y los jarros "aribaloides" Rojo Revestido Exterior-Negro Alisado Interior, a los que se une el tipo Yavi del componente altiplánico que también nos parece una expresión incanizada, pero del Noroeste Argentino (Figura 6). Por último, se encuentra presente el componente protoetnográfico a través de cerámica de pasta con mica.
Una característica importante de destacar en relación a esta primera instalación incaica es que Cerro Verde se emplaza en un área que, a juzgar por manifestaciones de arte rupestre y algunos restos superficiales aislados, fue ocupada previamente por grupos humanos asignables a las tradiciones tempranas. Esta situación es recurrente en el resto los asentamientos con impronta incaica.

La segunda instalación del Tawantinsuyu en la localidad corresponde al sitio que denominamos Incahuasi Inca, localizado en la quebrada homónima, al suroeste de Caspana, específica- 
mente en el tramo conocido como Laguna Verde. Este ha sido fechado en 1445 DC (UCTL 718; $550 \pm 50 \mathrm{AP}$ ) y en $1480 \mathrm{DC}$ (UCTL 719; 515 \pm 50 ), demostrando absoluta coincidencia con su asignación cultural y cronológica.

La ocupación tardía de la quebrada está documentada además por la presencia de complejos agrícolas diversos, compuestos por terrazas de cultivo en el talud, canchones planos y camellones o rumimokos ${ }^{15}$ en el valle del río. En las cercanías de los sistemas llamados rumimokos y sobre un promontorio rocoso, se ubica un conjunto habitacional intermitentemente ocupado hasta hoy para actividades mineras, cuya arquitectura sugiere cierta correspondencia con los momentos estudiados. Dicho conjunto se encuentra asociado a una mina de cobre, la cual se ha seguido explotando en la actualidad. Por último, subiendo aguas arriba de la quebrada hasta el sitio en cuestión y adosadas al farellón rocoso de ésta, se despliega un número considerable de estructuras para almacenaje. Debido a su completa semejanza formal con construcciones de uso etnográfico bastante reciente conocidas como trojas, son analogables a las collca del Tawantinsuyu.

Un ramal del camino imperial une, por lo menos, esta quebrada con la de Caspana a lo largo de un tramo aproximadamente de $8 \mathrm{~km}$ en línea recta (Varela 1999), lo cual se complementa muy bien con datos etnográficos que informan de un camino inca que desde Incahuasi se dirige al sur, pasando por Machuca y Río Grande, para después llegar a San Pedro de Atacama. Sin duda, ésta sería la ruta del principal ramal del inkañam en la vertiente occidental de los Andes.

Particularmente, la instalación Incahuasi Inca se emplaza en el margen suroeste de la quebrada, donde se construyó aterrazando la pendiente natural del talud y creando un plano en el punto de contacto de éste con el farellón rocoso (ver plano en Adán 1999: Fig. 5). Aquí se ubican 34 estructuras entre las que se distinguen unas de planta

15 De acuerdo al trabajo realizado en Panire, estos camellones pudieron construirse con el fin de conservar la humedad, distribuir el agua para el riego y regular los factores térmicos; todo esto, con el propósito de asegurar las mejores condiciones para el desarrollo de los cultivos en altura (Alliende et al. 1993).

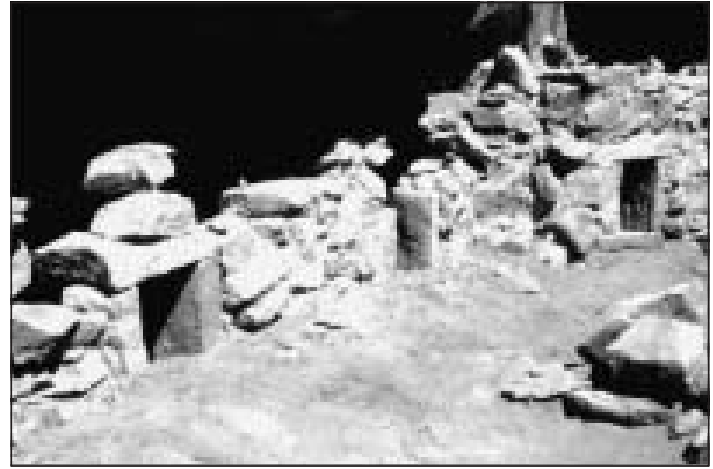

Figura 7. Collcas de Incahuasi Inca.

irregular y subrectangular, probables recintos y/o aterrazamientos de carácter habitacional; otras de planta cuadrada similares a las chullpa y de planta subrectangular adosadas al farellón asimilables a las trojas, con probabilidad, todas usadas como collca (Figura 7).

De acuerdo a lo anterior, la forma dominante de las construcciones es la irregular, seguida por las rectangulares y luego las subrectangulares con superficies que abarcan entre $\operatorname{los} 1.36 \mathrm{~m}^{2}$ y los $56.87 \mathrm{~m}^{2}$ (Adán 1999). La construcción de las collca del sitio, por su factura, técnicas y materiales, evidentemente se relaciona con las demás trojas de la quebrada, por lo tanto, corresponden al mismo momento constructivo, es decir, al Período Tardío. Esto es interesante, porque sus características arquitectónicas son diferentes a las del resto de las estructuras del sitio (recintos y terrazas), por lo cual su construcción debe obedecer a una planificación mayor. En cambio, las restantes edificaciones se hicieron con técnicas y un ordenamiento más espontáneo, repitiendo los patrones de las aldeas locales, señalándonos que su población sería la responsable de ellas (Adán 1999). Esto se traduce, al observar un plano del sitio, en un asentamiento aglutinado y compacto en el que, a primera vista, no se distinguen diferentes sectores espaciados; sin embargo, es evidente una organización del espacio que ubica las collca en el centro-arriba, las estructuras tipo chullpa en los extremos del mismo y los recintos/ aterrazamientos en el centro-abajo y desde donde se tiene al alcance una visión bastante completa del valle.

Otra importante característica de Incahuasi Inca, es la presencia abundante de expresiones de arte 
rupestre. Estas representaciones, en su totalidad, corresponden a pictografías que se distribuyen en el farellón rocoso a lo largo de $5 \mathrm{~m}$, pudiéndose distinguir hasta 15 paneles. En ellos se identificaron tres estilos pictóricos regionales (Vilches y Uribe 1999), dando cuenta de diferentes momentos ocupacionales. El primero de ellos hace uso del elemento "marco" realizado con líneas onduladas finas, dentro del cual se circunscribe una escena, generalmente protagonizada por figuras antropomorfas. Estas pinturas guardan estrechas semejanzas con diseños registrados en el sitio Cueva Blanca, en la quebrada del Ojalar, a partir de los cuales se ha podido establecer un estilo del mismo nombre que se data de manera indirecta entre 0-500 DC (Gallardo 1999). El segundo estilo del sitio estaría dado por pinturas blancas de seres antropomorfos de perfil portando "armas", cuyas bocas con colmillos adquieren la forma de un pequeño rectángulo que sobresale del perfil del rostro, producto de una proyección exagerada de las mismas. Este rasgo se asemeja a aquellas representaciones de guerreros con máscara felínica, propios de la Cultura Aguada del Período Medio del Noroeste Argentino (A. R. González 1972, 1977). Por último, el tercer estilo observado comprende los camélidos lineales rígidos típicos del Tardío, que esta vez fueron pintados en tres colores diferentes: negro, rojo y blanco. Tales expresiones conviven e incluso se superponen en el tiempo, debido a lo cual es posible detectar representantes de los tres grandes períodos agroalfareros: Temprano, Medio y Tardío (Vilches y Uribe 1999). Un aspecto relevante del último de éstos, de innegable filiación incaica, es la localización de las figuras al interior de las collca, siendo imposible verlos sino al interior de las mismas, y en las cuales se ha utilizado la misma arcilla ocupada en la construcción de las bodegas.

En relación al material lítico de superficie, se observa una depositación secundaria, derivada de desechos de talla y de facto, correspondiente a malaquita y restos de palas líticas de andesita (Uribe y Carrasco 1999). Los desechos de talla están representados, en particular, por lascas secundarias sin retoque, a pesar de lo cual no debe descartarse la talla en el sitio, la que queda evidenciada por la presencia de las lascas secundarias y de una pala reutilizada como yunque para percusión bipolar. Es importante señalar además, que en las andenerías, distantes unos $200 \mathrm{~m}$ de Incahuasi Inca, se recolectaron 12 puntas de proyectil fracturadas, en su mayoría de basalto, con pedúnculo enunciado y grande, aletas enunciadas y retoques bifaciales. Se agrega a lo anterior un raspador semilunar grande y dos lascas, con retoque facial y marginal doble, respectivamente, todo en la misma materia prima. Lo anterior, por supuesto, tiene connotaciones culturales tempranas previas al Intermedio Tardío e incluso precerámicas compartidas con el Loa Medio y el Salar de Atacama, lo que de nuevo estaría sugiriendo que los incas se han asentado sobre los restos de poblaciones mucho más antiguas que las del momento estudiado.

En tanto, otra vez el material cerámico recuperado dio cuenta del predominio del componente LoaSan Pedro debido a la presencia, como en el resto de los sitios, de los tipos Turi Rojo Alisado, Rojo Burdo, Aiquina, Turi Gris Alisado, Rojo Revestido Pulido y Rojo Revestido Exterior, los cuales forman la esencia de la alfarería local del Intermedio Tardío, compuesta por cántaros, cuencos, platos y ollas. Además, se registran otros como los tipos Dupont y San Pedro Rojo Violáceo, seguidos de manera bastante notoria por el componente altiplánico a través de tipos como Yavi en sus distintas expresiones, confirmando relaciones con el Noroeste Argentino durante esta época. Junto con este último tipo se presenta un componente incaico constituido por los tipos Turi Rojo Revestido Pulido Ambas Caras, Rojo Revestido Exterior-Negro Alisado Interior y la presencia de verdaderos aríbalos hechos con materias primas y técnicas propias de la cerámica del Loa (Uribe y Carrasco 1999). Por otro lado, igualmente notoria es la manifestación de un componente alfarero temprano, pues se han identificado los tipos Sequitor de la tradición negra pulida de San Pedro de Atacama, así como los tipos Loa Rojo Alisado y Los Morros que han sido definidos en este territorio (Sinclaire et al. 2000).

Por último, Vega Salada, la tercera instalación incaica en estudio, se localiza en la ladera sur de la quebrada del río Salado, en un sector aplanado y ancho del talud que ha permitido la formación de una pequeña vega, gracias a afloramientos de manantiales, hoy superficialmente secos. El sitio se encuentra en las coordenadas geográficas $22^{\circ}$ $18^{\prime}$ Lat. Sur y $68^{\circ} 9^{\prime}$ Long. Oeste, $500 \mathrm{~m}$ aguas arriba del centro minero de San Santiago explotado en tiempos históricos, pero actualmente abandonado. Contamos con dos dataciones para él, una de 1590 DC (UCTL 720; 405 \pm 30 AP) y la otra de 
1665 DC (UCTL 721; 330 440 AP), en principio, muy tardías para los efectos de esta investigación. No obstante, ello se debe a que las muestras fueron intencionalmente seleccionadas para documentar los eventos más recientes de la localidad (cerámica de pasta con mica). Con todo, su ocupación en momentos tan tempranos del contacto hispano-indígena nos permite suponer que el lugar también fue explotado por los incas como lo demuestran los restos materiales presentes.

Lo anterior es coherente con el patrón de asentamiento que, en la práctica, es idéntico al de Incahuasi Inca. De la misma manera que en éste, entre la mina y el asentamiento se encuentra un sistema de andenerías que se usó en forma agrícola. Aquí, sin embargo, se pueden distinguir con facilidad diferencias constructivas en cuanto materiales utilizados y el trabajo comprometido en ellos, lo cual se traduce en dos sectores de andenes que suponemos tienen implicancias cronológicas y culturales. El más cercano a la mina, exhibe terrazas de aspecto rústico hechas con piedras redondeadas iguales al resto que se detecta en la localidad; en cambio, las próximas al sitio son de piedras angulares, por lo cual parecen más elaboradas.

Pese a la inexistencia de collca a lo largo del transecto mina-instalación, las demás características son casi las mismas que exhibe Incahuasi Inca. Vega Salada se compone de estructuras pircadas dispuestas en dos niveles, uno sobre la meseta que se forma en el talud, y otro pegado al farellón rocoso, además de tres sectores que se pueden reconocer en la meseta misma. En la parte central de ésta se observan tres estructuras de planta rectangular, dos de ellas compartiendo un muro de hilada simple, mientras que el tercer recinto es independiente y ejemplifica la presencia incaica en el lugar. Este no se dispone siguiendo el curso de la quebrada como aquellas, presenta muros de doble hilada, relleno y mortero de argamasa, tiene forma trapezoidal y un vano de acceso en el centro del muro orientado hacia el este. Alrededor del conjunto se concentró toda la actividad, mientras que hacia ambos extremos se observan construcciones más sencillas, irregulares y de grandes dimensiones a manera de corrales con muy escasa depositación cultural. Hacia el extremo o sector poniente, se levantan dos pequeñas estructuras del tipo chullpa o torreón sobre un promontorio rocoso, ambas de planta cuadrangu- lar y vanos orientados al farellón, recordándonos las de Incahuasi Inca y los andenes contiguos, pues se han construido con la misma roca. Edificaciones como éstas se repiten a manera de trojas por todo el nivel superior del sitio e incluso hasta el extremo del sector oriental, donde se encuentra otra estructura tipo chullpa sobre una enorme roca, pero de planta más irregular, hecha con bolones y su vano orientado hacia la quebrada. Las trojas se construyen en este sector aprovechando las oquedades del farellón y son de menores dimensiones.

En definitiva, de nuevo nos encontramos frente a una organización del espacio que implica un centro con divisiones arriba-abajo, también presente en Cerro Verde, y dos extremos marcados por torreones. Pero, además, de la misma manera que en aquel y en cierta medida en Incahuasi Inca, destaca la elección de un sector plano para la construcción del asentamiento. Por lo demás, en los tres casos, la localización indica que se desarrollaron actividades mineras, agrícolas y/o ganaderas.

Respecto a lo último, es interesante notar que la ocupación desarrollada en Vega Salada, en especial su explotación agrícola, no se encuentra conectada con ningún otro asentamiento de la población local en la quebrada del río Salado. Estos todavía son inexistentes, al parecer, porque aquí el agua es sumamente salobre. Lo anterior sugiere que bajo la influencia del Imperio, en la localidad de Caspana como en otras partes del Tawantinsuyu, se optimizan o generan nuevas tierras agrícolas, antes menospreciadas y subexplotadas por la población local. En este caso, adquieren importancia los manantiales de Vega Salada que, aplicando conocimientos novedosos, se usaron para alimentar los canales de las terrazas, así como también pudieron introducirse especies vegetales resistentes a la calidad del agua (Alvarez 1997). En suma, se intentaría potenciar al máximo la productividad de los espacios, por lo cual las nuevas conquistas establecerían esta clase de instalaciones para su control, pese a su alejamiento de la vía principal de la expansión, puesto que Vega Salada se introduce hacia el oriente de dicha ruta. Sin duda, su existencia también puede estar relacionada con la dinámica incaica y la población que habitaba el contiguo río Toconce (Aldunate y Castro 1981).

De acuerdo al material lítico presente en superficie, las materias primas son en su totalidad 
alóctonas, salvo los trozos de malaquita y el mineral de cobre; en tanto, la producción de artefactos está dirigida fundamentalmente a la actividad agrícola (Uribe y Carrasco 1999). Las categorías y materias primas más representadas son los microdesechos y las lascas primarias en andesita. Tal situación, junto con la frecuente presencia de palas del mismo material y fragmentos de ellas, dan cuenta de un evidente y continuo reavivado de filos de los artefactos agrícolas. La cercanía del complejo de andenes de cultivo con el sitio habitacional sugiere un continuo traslado de herramientas de un lugar a otro para su cuidado y mantención. Tampoco se puede desestimar que tales instrumentos hayan sido usados en labores mineras, puesto que sólo se explotaron las vetas superficiales (Díaz 1998 Ms).

El material cerámico de superficie recuperado en Vega Salada presenta la más alta variabilidad tipológica de las instalaciones incaicas, aunque se mantiene el predominio del componente local LoaSan Pedro (Uribe y Carrasco 1999). Se registraron los tipos Turi Rojo alisado, Rojo Burdo, Aiquina, Turi Gris Alisado, Rojo Revestido Pulido y Rojo Revestido Exterior, a los que se unen los platos Dupont del mismo componente y el ya incanizado Rojo Revestido Exterior-Negro Alisado Interior. Se aprecia, por otra parte, un claro aumento del componente protoetnográfico, característica que comparte con el sitio Estancia Mulorojte y que le imprime gran diversidad a su material. En tanto, del componente altiplánico se distinguen los tipos Hedionda y Yavi, este último de época incaica. Por lo tanto, dicho componente aparece compuesto por las manifestaciones locales de la región y del Noroeste Argentino, de la misma manera que en el resto de los sitios estudiados.

Por último, es igualmente destacable que la instalación fue construida sobre ocupaciones previas al Intermedio Tardío como en los casos anteriores, asignables a las tradiciones culturales arcaicas o formativas tempranas. Esta situación quedó documentada a partir de la cerámica superficial y por el material recuperado en excavaciones donde aparecieron fragmentos asignables a esos momentos, del mismo modo que por cierto material lítico y arte rupestre de las cercanías (Uribe y Carrasco 1999; Vilches y Uribe 1999). En cualquier caso, los asentamientos propiamente incaicos muestran una tendencia a establecerse inmediata- mente sobre ocupaciones muy antiguas, llegando incluso a alterarlas con su presencia, la cual no es tan evidente en los sitios de la población local.

\section{Cementerio de Los Abuelos: El espacio compartido}

La tercera clase de yacimientos que hemos seleccionado para realizar nuestra investigación corresponde al sitio funerario conocido como el Cementerio de los Abuelos, mencionado en la literatura especializada por distintos autores (Le Paige 1958; Núñez 1965; Barón 1979). ${ }^{16}$

El cementerio está constituido por más de 70 construcciones subcirculares de piedra (Figura 8), de no más de $1 \mathrm{~m}$ de altura, con vanos a la manera de las torres que llamamos estructuras tipo chullpa, parecidas a las trojas o silos que se encuentran en los farellones de las quebradas, así como a las sepulturas en abrigos rocosos que serían características de este territorio (Aldunate y Castro 1981). Particularmente, en este caso, la mayor cantidad de tumbas se encuentran adosadas a grandes bloques desprendidos del farellón rocoso del cañón, pero también se observan varias otras levantadas de manera independiente, debido a lo cual se parecen aún más a las chullpa. Otras no presentan ningún tipo de estructura como parece ocurrir en la mayoría de las incaicas y las coloniales tempranas. Podríamos decir que en su totalidad son colectivas, en gran medida, porque el sitio fue usado con el mismo propósito hasta los primeros momentos del dominio español (Barón 1979).

El sitio se localiza en las mismas coordenadas del pueblo de Caspana y a una altura de 3260 m.snm. Se emplaza en la ladera noreste de la quebrada donde posteriormente en épocas coloniales e históricas se edifican el sector llamado Pueblo Viejo, la iglesia católica y el cementerio antiguo, fren-

\footnotetext{
16 Por el momento, nuestras apreciaciones del sitio derivan de estas fuentes, debido al grado de alteración que presenta y a que, por respeto a la comunidad indígena, no hemos querido desarrollar nuevos trabajos de terreno hasta que se concluya el estudio de los materiales que ya se han recuperado, como las colecciones Emil de Bruyne del Museo Nacional de Historia Natural de Santiago y la obtenida por Barón y Serracino, depositada en el Museo de Caspana. Por lo mismo, aún no contamos con fechados absolutos para el sitio.
} 


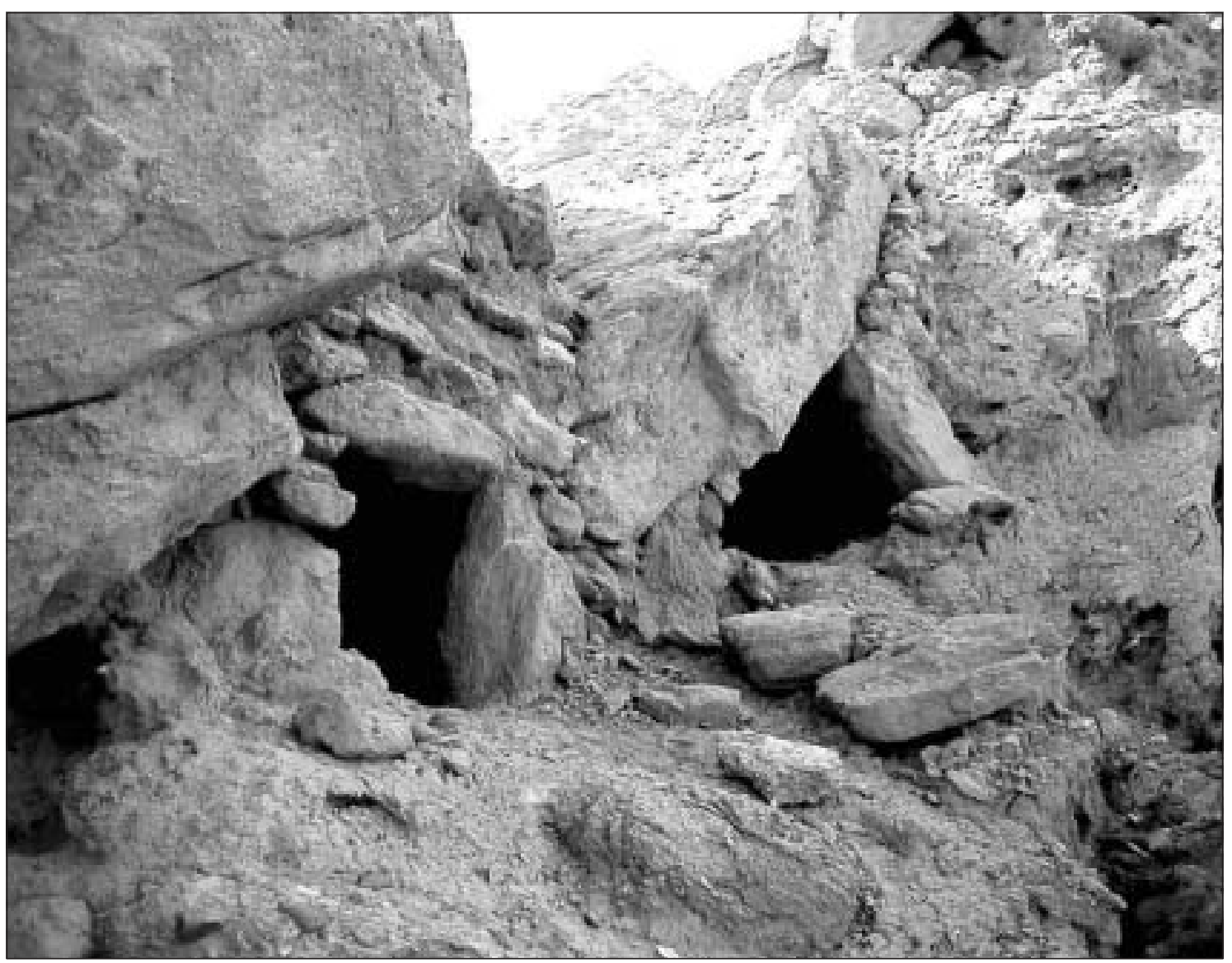

Figura 8. Sepulturas asociadas a bloques rocosos.

te al pueblo actual. El estudio de los materiales recuperados por otros investigadores nos sugieren que el cementerio fue usado sólo a partir del Período Intermedio Tardío, sin embargo, desde ese momento en adelante la actividad fue constante, perdurando hasta las épocas coloniales mencionadas. A través de la cerámica, esto se traduce en una secuencia que comprende: 1) el Intermedio Tardío inicial que se refleja en la considerable frecuencia del tipo Dupont; 2) el Intermedio Tardío clásico representado por el tipo Aiquina y ejemplares de tradición altiplánica meridional (tipo Hedionda); 3) el Intermedio Tardío final en el cual aparecen expresiones locales altiplanizadas junto a la alfarería tradicional; 4) el Período Tardío con un destacable número de piezas inca locales, además de aquellas del Noroeste Argentino, y 5) uno Colonial Temprano que parece derivar no sólo del contacto hispano-indígena, sino también del momento anterior, ya que a partir de aquella época la alfarería experimenta transformaciones tanto en formas como materias primas que tienden a mantenerse incluso en la actualidad (p.e., pastas con mica; Uribe y Carrasco 1999).

Es posible distinguir que en ciertas tumbas, las ofrendas combinan piezas de cerámica local, de tradición altiplánica, inca local, inca foránea (p.e., del Noroeste Argentino) y, con probabilidad, hasta cusqueña. Lo anterior definiría a este espacio como el lugar privilegiado para el encuentro y expresión de las distintas manifestaciones culturales que caracterizan el período, dando cuenta de un contexto donde se aceptan las diferencias y se releva la diversidad. Esto también lo sugiere, en el caso incaico, la presencia de otros materiales que se ajustan a los patrones estilísticos cusqueños, como, por ejemplo, la metalurgia aquí presente a través de alfileres o topus, entre otros.

La exposición del registro arqueológico que hemos realizado nos indica una concentración y 
variedad de sitios, cerámica, arquitectónica y vialmente conectados con el importante e imponente Pucara de Turi (Aldunate 1993; Castro et al. 1993). Tal situación nos hace pensar en la existencia de un circuito de yacimientos cuya distribución espacial, así como su jerarquización funcional y situación contextual, podrían dar respuestas sobre los intereses, pero principalmente sobre las estrategias de ocupación y dominio de los espacios locales por parte del Tawantinsuyu. Sin duda, un requisito importante fue el proceso de negociación con las poblaciones de este territorio, el que no necesariamente pudo desenvolverse a través de la presencia violenta de numerosos ejércitos. Más bien, parecen operar mecanismos políticos más sutiles, en conocimiento de estas poblaciones locales del mundo andino, que disminuirían la violencia física y aumentarían la eficiencia simbólica de los encuentros. Creemos que un buen reflejo de ello sería la situación brevemente descrita del Cementerio de Los Abuelos, puesto que aquí se habrían enterrado varios de los protagonistas de este proceso, demostrando el éxito del Tawantinsuyu en estas tierras.

\section{Comentarios y conclusiones}

En nuestra opinión y tal como lo señalábamos en la introducción, uno de los requerimientos fundamentales para desarrollar la problemática incaica como una línea de investigación consolidada era su tratamiento en sí misma, superando así el desinterés que ha recibido en el país. Al amparo de este requerimiento metodológico, una de las preocupaciones fundamentales de nuestro estudio, ha sido recopilar la mayor cantidad de antecedentes arqueológicos de los sitios reconocidos como incaicos o impactados por el Imperio, al mismo tiempo que comprender la historia cultural de Caspana y la situación en que se encontraban sus poblaciones al momento de incorporarse a éste. Este conjunto de antecedentes, referidos entre otros temas al emplazamiento de los yacimientos, la caracterización de su arquitectura, la funcionalidad de las estructuras y las características de la depositación de determinados materiales culturales, nos han permitido comenzar a delinear una interpretación propia sobre el dominio del Tawantinsuyu en las tierras altas del río Loa.

En este sentido, nuestra investigación se orientó a proponer un modelo alternativo acerca de la presencia incaica en estas latitudes, privilegiando una mirada desde la antropología política que tiende a reconocer tras las diversas formas de cultura material del Tawantinsuyu, un comportamiento ideológicamente consciente de su expansión. Por lo tanto, creemos que las poblaciones del Período Intermedio Tardío de Caspana, como las del resto del curso superior del río Loa, estuvieron bajo el dominio incaico directo en cuanto un Estado que decide estar e imponer presencia, utilizando diversos mecanismos y, por consiguiente, diversas expresiones que dan cuenta de una compleja situación simbólica, política y culturalmente significativa para los diferentes actores de este proceso.

Profundizar el conocimiento de las expresiones materiales del encuentro entre la población local e incas, incluida la negociación del dominio político entre ambas entidades, es una tarea por hacer. No obstante, es consenso que este encuentro implica poner en juego la particular concepción de las relaciones sociales del mundo andino, inserta dentro de una construcción cultural de la realidad que se basa en un sistema de oposiciones complementarias muchas veces extensivo a su cultura material (Platt 1987; Cereceda 1990; Martínez 1995). Lo anterior, en una primera aproximación a nuestro caso, se expresaría a través de las clases de sitios arqueológicos que hemos descrito in extenso, los cuales manifiestan una oposición sugerente: sitios exclusivamente incaicos, con elementos locales, y sitios exclusivos de la población local con intrusiones incaicas. En el cercano e imponente Pucara de Turi este sistema de oposiciones se observa incluso al interior del mismo asentamiento, generando principios de exclusión e inclusión con relación a la cultura original que darían cuenta de las formas de apropiación de este espacio y su control político-simbólico (Gallardo et al. 1995). Dicha situación puede ser ampliada a un nivel intersitios a juzgar por el circuito de yacimientos localizados en Caspana, como lo vislumbraron otros colegas desde una perspectiva aún más general que compromete a toda la región (Cornejo 1995).

Con un panorama como éste, el tema del encuentro y la negociación surge como uno de los más recurrentes y que, por lo tanto, habría que considerar al momento de adentrarse en el problema (Martínez 1994). Más particularmente, gracias a trabajos como los de Platt (1987), sabemos que las sociedades del Altiplano Meridional y Circumpuna poseen un concepto de sociedad y 
relaciones humanas donde predominan los principios de reciprocidad y redistribución para construir estrategias muy sutiles, pero al mismo tiempo eficaces, de dominación y control social. En ellas la reciprocidad no sólo opera a nivel económico, sino también a nivel social, político y religioso posibilitando una gran efectividad de dichas estrategias sin la necesidad de un Estado. Como señala el autor, por más asimétrica que fuese la reciprocidad, estos grupos humanos impidieron internamente que se alterara el orden social y que se transitara a una situación de jerarquización extrema que apoyara el surgimiento de dicha organización sociopolítica, la cual por esta vía derivaría en la formación de las agrupaciones conocidas como federaciones aymara.

Estas estrategias que impidieron el dominio político total de un grupo sobre otro, permitiendo cierta autonomía de los componentes de estas grandes alianzas interétnicas y de sus ayllo, formando sociedades segmentarias, fueron transformadas por el Estado incaico en mecanismos de dominación al ser utilizadas por éste de manera muy hábil, principalmente, a través de la redistribución, es decir, la imposición de su "generosidad". El Tawantinsuyu haría uso de los principios de reciprocidad y redistribución, así como de todo su potencial económico para poner en "deuda" a las poblaciones locales que le interesó conquistar con el objeto de acceder a sus espacios, recursos y gentes. Seguramente, como su "dar" resultó mucho mayor al de los grupos dominados, a éstos les fue imposible "devolver la mano", quedando indefinidamente endeudados, por lo tanto, en condiciones obligadas de aceptar cualquier "petición y ruego" del Inka. En este contexto, parece ser más importante la presencia directa en cuanto Estado y, por consiguiente, el poder simbólico representado por éste y su materialidad frente a las unidades sociales (Uribe 1996), más que la acción mediatizada de otros grupos, sin perjuicio de su ocurrencia. ${ }^{17} \mathrm{Al}$ mismo tiempo, dentro de esta práctica, su comportamiento en los poblados ha-

17 Una situación interesante al respecto, es la frecuente presencia e importancia que adquieren los relatos referidos a la historia del "Rey Inka" en la memoria oral de los caspaneños. La figura del Inka, además de representar valores políticos durante las rebeliones indígenas del siglo XVIII y de ser reivindicada por estos movimientos sociales, evoca un pasado glorioso, un pasado memorable (Castro y Varela 2000). bría alterado en forma explícita los sectores asociados a la religiosidad local -por ejemplo, áreas de chullpa como ocurrió en el Pucara de Turi o el mismo Cementerio de Los Abuelos-, abarcando de esa manera todo el espectro de relaciones sociales, incluidas las sagradas. Por lo mismo, la transformación de tales espacios de las poblaciones locales parece ser uno de los recursos o gestos más fuertes de su dominación, sobre todo porque es allí donde finalmente se resuelve la reciprocidad, entre las divinidades y el Inka, pues son las que controlan el orden del cosmos (p.e., el agua, los cultivos, el ganado). En este sentido, a través de la apropiación de los espacios sagrados se percibe la legitimación de su poder, explicitando con ello la naturaleza divina del Estado cusqueño.

Con estas estrategias, el Tawantinsuyu parece haber "creado cultura" en los espacios de otros en favor de sí mismo, pero dejando también algunos relativamente "libres" para que los conquistados desarrollaran la "autonomía" a la que estaban acostumbrados. De esta manera, se separaron espacios de unos y otros como mencionan documentos coloniales e investigadores: Estado, iglesia y comunidad (Murra 1978). Entre los primeros, se encontrarían sitios como Cerro Verde, Incahuasi Inca y Vega Salada, mientras que pertenecientes a los últimos serían Talikuna y Mulorojte, dejando vislumbrar que a pesar de no ocupar la totalidad de éstos, en ningún caso se marginan ni menos se despreocupan de su control.

Las evidentes diferencias arquitectónicas entre los sitios, como la selección del lugar de los asentamientos, evidencia una forma de dominio plástico que permite la aparición de espacios privativos de los incas y otros aparentemente libres de su materialidad. A pesar de eso, la depositación cerámica en sectores acotados de las instalaciones indica la realización de actividades comunales donde convergió la población local y, seguramente, donde se recrearon eventos y protocolos rituales para ejercer el acto de reciprocidad. Por otra parte, la presencia, a veces imperceptible, en la misma depositación alfarera de los sitios, da cuenta de lo sutil del dominio que transparenta un ejercicio de poder elaborado y eficiente.

Al amparo de estas ideas, sucintamente desarrolladas, vemos ordenarse la evidencia material del Tawantinsuyu en estas tierras, dándole coherencia regional al comportamiento de los yacimien- 


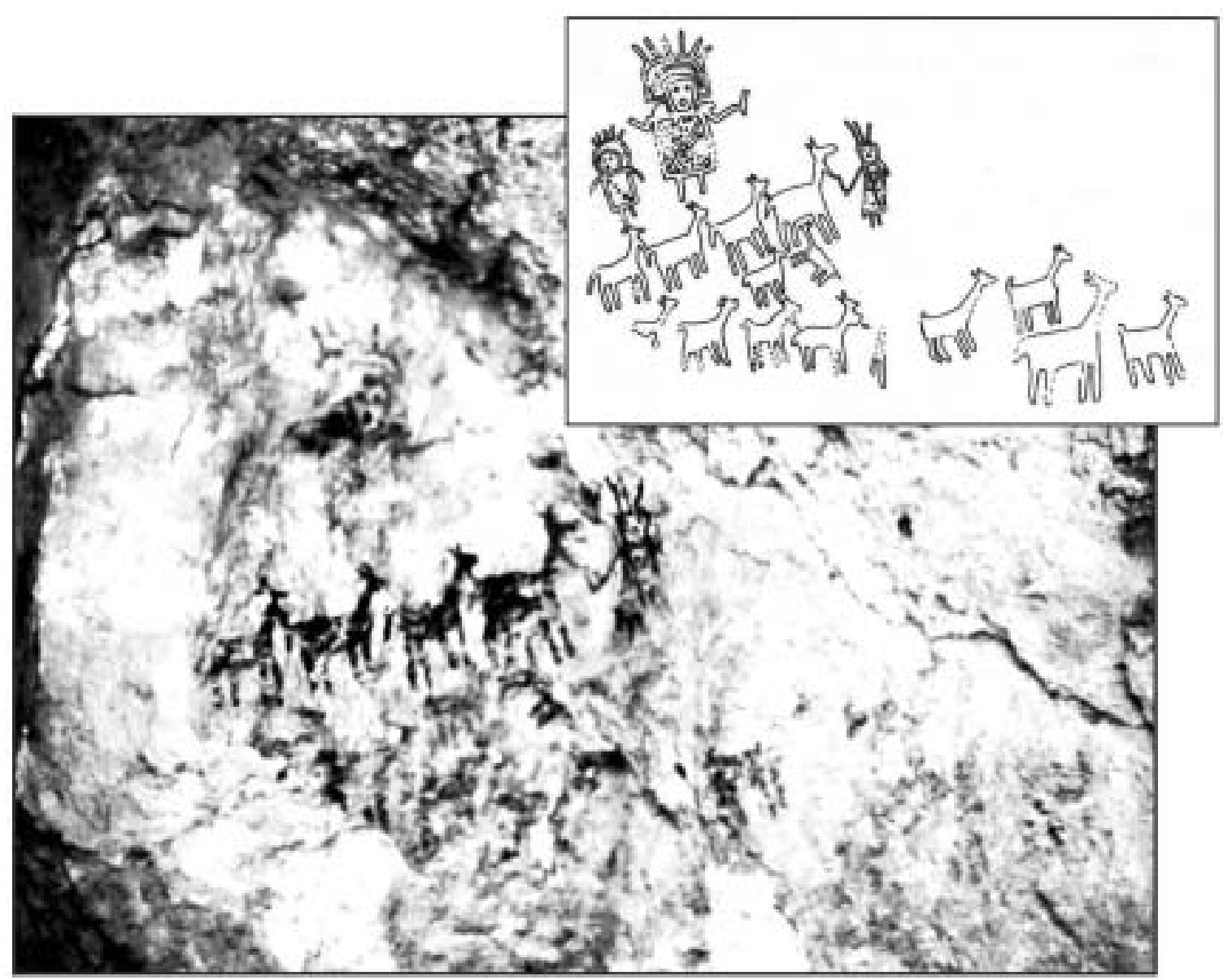

Figura 9. Pictografía asociada al Inka. Cueva del Diablo, Caspana.

tos donde se aprecia su impronta. Esta incluso parece ser más fuerte y abundante que la pensada hasta el momento para un área a primera vista tan inhóspita y "pobre", a juzgar por el gran despliegue arquitectónico y un tenue, pero recurrente, repertorio cerámico. La presencia incaica se hace evidente en aldeas locales como Talikuna exclusivamente a partir de la alfarería; en otras como el Pucara de Turi, además se llevan a cabo intervenciones mayores como fue la construcción de una callancahuasi o gran galpón de carácter ceremonial y civil; por último, en lugares como Cerro Verde se edifica sobre un espacio nuevo e íntegramente de acuerdo a los patrones cusqueños, levantándose estructuras del más alto valor simbólico para el Inka como un ushnu. En este contexto, el caso de la arquitectura $-y$ el arte rupestre (Figura 9)- es bastante elocuente para mostrar que la intención de estas ocupaciones es denotar simbólica y políticamente con elementos de la cultura ma- terial que sean significativos para ambas partes involucradas en este arreglo (Adán 1996).

Sin duda, el conjunto de sitios que se registraron en Caspana son de vital importancia para estudiar y poner a prueba estas ideas, pero también para sistematizar otros registros e hipótesis relacionados con la expansión del Tawantinsuyu en la región y el resto del Norte Grande de Chile, introduciéndonos en la comprensión de los principios que modelaron dicho desplazamiento. Esto, porque son escasas las investigaciones actualizadas directamente relacionadas con el tema, a pesar de la abundante información arqueológica, etnohistórica y oral existente sobre el mismo. Más aún, que accedan a un plano distinto de análisis dentro de la interpretación arqueológica, más allá de las analogías entre explotación de riquezas minerales y expansión (Silva 1985) o señoríos altiplánicos y dominio (Llagostera 1976). De esta manera, 
proponemos trasladar la discusión a un marco interpretativo que integre las asociaciones materiales mencionadas con la concepción planifica$\mathrm{da}$, directa, diferencial y socialmente funcional del dominio incaico, más de lo que hasta ahora ha sido argumentado. Incluso, creemos que identificando los distintos comportamientos del material incaico en los sitios es posible establecer una periodificación de la expansión, por lo menos a este territorio, distinguiendo etapas en dicho proceso. En este sentido, los poblados locales deben contener las primeras muestras del encuentro, pues aquí debieron desarrollarse las negociaciones donde el Inka desplegó toda su capacidad de "dar".

En definitiva, los argumentos teóricos y empíricos que sustentan la comprensión de esta problemática se han convertido en el marco de referencia para profundizar de manera más detallada en el tema, y descubrir los restos materiales que habrían acompañado o derivado de los mecanismos políticos desplegados por el Inka, en su afán de conquista de las tierras altas del río Loa.

Agradecimientos Toda nuestra gratitud a la comunidad indígena de Caspana por acostumbrarse a nuestras continuas visitas y aceptarnos; pero, sobre todo, a Julián Colamar, gran atacameño, que en el año 1998 nos dejó para siempre. A todos los que han participado en las distintas campañas que iniciamos a partir de 1994 en Caspana, financiados por FONDECYT. Destacamos la constante presencia de los colegas y amigos Patricia Ayala, Carlos Carrasco, Viviana Manríquez, Pablo Miranda y Varinia Varela, así como el apoyo incondicional de Victoria Castro gracias a quien, en gran medida, debemos nuestra llegada a las tierras del Loa.

\section{REFERENCIAS CITADAS}

ADAN, L., 1996. Arqueología de lo cotidiano. Sobre diversidad funcional y uso del espacio en el Pucara de Turi. Memoria para optar al Título Profesional de Arqueóloga. Departamento de Antropología, Facultad de Ciencias Sociales, Universidad de Chile, Santiago.

1996 Ms. Prospección de la Localidad de Caspana. Registro de Sitios. Informe Proyecto FONDECYT 1940097, Santiago.

1999. Aquellos antiguos edificios. Acercamiento arqueológico a la arquitectura prehispánica tardía de Caspana. Estudios Atacameños 18: 13-33.

ADAN, L. y M. URIBE, 1995. Cambios en el uso del espacio en los períodos agroalfareros: Un ejemplo en ecozona de quebradas altas, la localidad de Caspana. Actas del II Congreso Chileno de Antropología, pp. 541-555. Santiago.

ADAN, L., M. URIBE, P. ALLIENDE y N. HERMOSILLA, 1995. Entre el Loa y San Pedro: Nuevas investigaciones arqueológicas en Caspana. Hombre y Desierto 9, T II: 147-155.

AGURTO, S. 1987. Estudio acerca de la construcción, arquitectura y planeamiento incas. Cámara Peruana de la Construcción, Lima.

ALdunATE, C., 1993. Arqueología en el Pucara de Turi. Boletín Museo Regional de la Araucanía 4 (2): 61-78.

ALDUNATE, C. y V. CASTRO., 1981. Las chullpas de Toconce y su relación con el poblamiento altiplánico en el Loa Superior. Período Tardío. Tesis para optar al grado de Licenciado en Filosofía con mención en Prehistoria y Arqueología. Facultad de Filosofía, Humanidades y Educación, Universidad de Chile, Santiago.

ALLIENDE, P., V. CASTRO y R. GAJARDO, 1993. Panire: Un ejemplo de tecnología agrohidraúlica. Boletín Museo Regional de la Araucanía 4: 123-128.

ALVAREZ, L., 1997. Ocupación etnoandina del espacio en valles dulces y salados del extremo norte de Chile. Actas II Congreso Chileno de Antropología T II: 556-558. Santiago.

AYALA, P., 2000a. Revaluación de las tradiciones culturales del Período Intermedio Tardío en el Loa Superior: Caspana. Memoria para optar al Título Profesional de Arqueóloga. Departamento de Antropología, Facultad de Ciencias Sociales, Universidad de Chile, Santiago.

-2000b. Apropiación y transformación de arquitectura altiplánica en el Loa Superior: La aldea de Talikuna. Actas del XIV Congreso de Arqueología Chilena, pp. 793-813, Copiapó.

BARON, A. M., 1979. Excavación de un cementerio: Sus potencialidades. Tesis de Grado en Arqueología y Prehistoria. Universidad de Chile, Santiago.

BITTMAN, B., G. LE PAIGE y L. NUÑEZ, 1978. Cultura atacameña. Colección Culturas Aborígenes, Serie Patrimonio Cultural Chileno. División de Extensión del Ministerio de Educación, Santiago. 
CASTRO, V., 1992. Nuevos registros de la presencia inca en la Provincia de El Loa, Chile. Gaceta Arqueológica Andina VI (21): 139-154.

CASTRO, V. y V. VARELA., 2000. Los caminos del "Reinka" en la región del Loa Superior. Desde la etnografía a la arqueología. Actas del XIV Congreso de Arqueología Chilena, pp. 815-839. Copiapó.

CASTRO, V., F. MALDONADO, y M. VASQUEZ, 1993. Arquitectura en el Pucara de Turi. Boletín Museo Regional de la Araucanía 4 (2): 79-106.

CARRASCO, C., 1996. Ocupaciones tempranas en la localidad de Caspana, II Región. Boletín de la Sociedad Chilena de Arqueología 23: 20-22. Santiago.

CERECEDA, V., 1990. A partir de los colores de un pájaro... Boletín del Museo Chileno de Arte Precolombino 4: 57104.

CORNEJO, L., 1995. El inca en la región del río Loa: Lo local y lo foráneo. Hombre y Desierto 9, T I: 203-213.

DIAZ, A., 1998 Ms. Situación geometalogénica de la localidad de Caspana y sitios arqueológicos asociados. Visión preliminar. Informe FONDECYT 1970528, Santiago.

GALLARDO, F., 1999. Arte, arqueología social y marxismo: Comentarios y perspectivas (II Parte). Boletín de la Sociedad Chilena de Arqueología 27: 33-43.

GALLARDO, F. y F. VILCHES, 1995. Nota acerca de los estilos de arte rupestre en el Pucara de Turi (norte de Chile). Boletín de la Sociedad Chilena de Arqueología 20: $26-28$.

GALLARDO, F., M. URIBE y P. AYALA, 1995. Arquitectura inca y poder en el Pucara de Turi, norte de Chile. Gaceta Arqueológica Andina III (2): 151-171.

GONZALEZ, A. R., 1972. The felinic complex in Northwest Argentina. The cult of the feline, a conference in preColumbian iconography. Dumbarton Oaks Research Library and Collections, pp. 117-138. Washington D. C.

_-1977. Arte precolombino de la Argentina. Editorial Filmediciones Valero, Buenos Aires.

GONZALEZ, C., 1996. El criterio monumentalista y su aplicación a la arquitectura inca de Chile Central. Boletín de la Sociedad Chilena de Arqueología 23: 33-37.

LATCHAM, R., 1928. La prehistoria chilena. Sociedad Impresora y Litográfica Universo, Santiago.

LE PAIGE, G., 1958. Antiguas culturas atacameñas en la cordillera chilena (II parte). Anales de la Universidad Católica de Valparaíso 4 y 5, Santiago.

LLAGOSTERA, A., 1976. Hipótesis sobre la expansión incaica en la vertiente occidental de los Andes Meridionales. Homenaje al Dr. Gustavo Le Paige s. j., L. Núñez (Ed.), pp. 203-218. Universidad del Norte, Antofagasta.
MANRIQUEZ, V., 1999-2000. Proposiciones sobre la existencia de "identidad" o "identidades" en la localidad colonial de Caspana. Revista de Historia Indígena 4: 103-125.

MARTINEZ, J. L., 1994. Rituales fallidos, gestos vacíos: Un desencuentro entre españoles y andinos en 1532. Mundo Precolombino 1: 28-41.

1995. Autoridades en los Andes, los atributos del Señor. Pontificia Universidad Católica del Perú, Fondo Editorial 1995, Lima.

MOSTNY, G., 1949. Ciudades atacameñas. Boletín del Museo Nacional de Historia Natural 24: 125-201.

_1971. Prehistoria de Chile. Editorial Universitaria, Santiago.

MUÑOZ, I. y J. CHACAMA, 1993. El Inka en la Sierra de Arica. Boletín Museo Regional de la Araucanía 4: 269284.

MURRA, J., 1975. Formaciones económicas y políticas del mundo andino. Instituto de Estudios Peruanos, Lima.

1978. La organización económica del Estado Inka. Editorial Siglo XXI, México D. F.

NUÑEZ, L., 1965. Prospección arqueológica en el norte de Chile. Estudios Arqueológicos 1: 9-35.

-1981. Asentamiento de cazadores recolectores tardíos de la Puna de Atacama: Hacia el sedentarismo. Chungara 8: 137-168.

1992. Cultura y conflicto en los oasis de San Pedro de Atacama. Editorial Universitaria, Santiago.

NUÑEZ, L., y T. DILLEHAY., 1995. Movilidad giratoria, armonía social y desarrollo en los Andes Meridionales: Patrones de tráfico e interacción económica. Universidad Católica del Norte, Antofagasta.

NUÑEZ, P., 1993. Posibilidades agrícolas y población del incario en el área atacameña. Norte de Chile. Boletín Museo Regional de la Araucanía 4: 259-268.

PLATT, T., 1987. Entre ch'axwa y muxsa. Para una historia del pensamiento político aymara. En Tres reflexiones sobre el pensamiento andino, J. Medina (Ed.), pp. 61-32. HISBOL, La Paz.

POLLARD, G., 1982 [1970]. The cultural ecology of ceramic stages settlement in Atacama Desert. Doctoral Dissertation, Columbia University Microfilms int., Ann Arbor.

RAFFINO, R., 1981. Los incas del Collasuyu. Ramos Americana Editores, La Plata, Buenos Aires.

SCHIAPPACASSE, V., V. CASTRO y H. NIEMEYER, 1989. Los Desarrollos Regionales en el Norte Grande (1000 a 1400 DC). En Culturas de Chile. Prehistoria. Desde sus orígenes hasta los albores de la conquista, J. Hidalgo, 
V. Schiappacasse, H. Niemeyer, C. Aldunate e I. Solimano (Eds.), pp. 181-220. Editorial Andrés Bello, Santiago.

SILVA, O., 1979 Ms. Informe de Avance de las investigaciones del centro ceremonial de Cerro Verde (Talikuna 4), Provincia el Loa. Informe Proyecto DTI-UCH S459-791, Santiago.

_ 1985. La expansión incaica en Chile: Problemas y reflexiones. Actas del IX Congreso Nacional de Arqueología Chilena, pp. 321-340. Museo Arqueológico de La Serena, La Serena.

SINCLAIRE, C., M. URIBE, P. AYALA y J. GONZALEZ, 2000. La alfarería del Período Formativo en la región del Loa Superior: Sistematización y tipología. Actas del XIV Congreso Nacional de Arqueología Chilena, pp. 285-314. Copiapó.

URIBE, M., 1996. Religión y poder en los Andes del Loa: Una reflexión desde la alfarería (Período Intermedio Tardío). Memoria para obtener el Titulo Profesional de Arqueólogo, Departamento de Antropología, Facultad de Ciencias Sociales, Universidad de Chile, Santiago.

1999. La arqueología del Inka en Chile. Revista Chilena de Antropología 15: 63-97.
URIBE, M. y L. ADAN, 1995. Tiempo y espacio en Atacama: La mirada desde Caspana. Boletín de la Sociedad Chilena de Arqueología 21: 35-36.

URIBE, M. y C. CARRASCO, 1999. Tiestos y piedras talladas de Caspana. La producción alfarera y lítica en el Período Tardío del Loa Superior. Estudios Atacameños 18: $55-71$.

VARELA, V., 1992. De Toconce pueblo de alfareros a Turi pueblo de gentiles. Un estudio de etnoarqueología. Tesis para obtener el Título Profesional de Arqueóloga, Departamento en Antropología, Facultad de Ciencias Sociales, Universidad de Chile, Santiago.

- 1999. El Camino del Inka en la cuenca superior del río Loa, Desierto de Atacama, norte de Chile. Estudios Atacameños 18: 89-105.

VARELA, V., M. URIBE y L. ADAN, 1993. La cerámica arqueológica del sitio 02-TU-001: "Pucara" de Turi. Boletín del Museo regional de la Araucanía 4, T II: $107-$ 121.

VILCHES, F. y M. URIBE, 1999. Grabados y pinturas del arte rupestre tardío de Caspana. Estudios Atacameños 18: 73-87. 